\title{
UMA NOVA ABORDAGEM PARA ANÁLISE DA OPACIDADE DO PAPEL
}

\author{
MARIA APARECIDA CARPIM
}

Orientador: Prof. Dr. LUIZ ERNESTO GEORGE BARRICHELO

Dissertação apresentada à Escola Superior de Agricultura "Luiz do Queiroz", da Universidado de São Paulo, para obtenção do título de Mestre em Engenharia Florestal.

PIRACICABA

Estado de São Paulo - Brasil

Dezembro - 1986 
. ii

Aos meus pais, Sillvío e Joama e ao meu noivo, marcos

DEDICO 


\section{AGRADECIMENTOS}

Ao Prof.Dr. Luniz Ermesto George Barrichelo, pela orientação e dedicação.

Ao. Dr. Ergilio Clamdio-da-Silva UIr., pelo apoio e constante incentivo.

Ao Engo Ric cardo luniz de Vascomcellos Dinas, pelas sugestões.

A Escolla Superior de Agricunturra Iuniz de queiroz e ao Departamemto de Ciemcias Florestais, pela oportunidade.

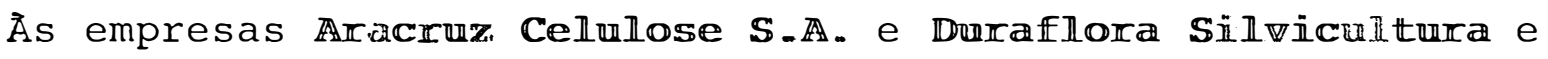
Commércio $\mathbb{L}_{\text {tda, }}$ pelo fornecimento do material e apoio.

Aos funciomários do Cemtro de Pesquisas e mecmologia da AraCrruz Celnlose S.A. e do Departamemto de Ciemcias Frlorestais, pelo auxílio na parte experimental do trabalho.

Ao Comsellino Naciomall de Desemvolivimemto Ciemtifico e Tecmoló gico (CNPq) e a Fumdaça de São Panlo ( $\mathbb{P} \mathbb{A} \mathbb{P} \mathbb{E} \mathbb{P})$, pelo suporte financeiro necessário a rea lização do trabalho. 
A todos que direta ou indiretamente contribuiram para realização deste trabalho. 
RESUMO

vii

SUMMARY $i x$

1. INTRODUÇ̃̃o $\ldots \ldots \ldots \ldots \ldots \ldots \ldots \ldots \ldots \ldots \ldots$

2. OBJETIVOS $\ldots \ldots \ldots \ldots \ldots \ldots \ldots \ldots \ldots \ldots \ldots \ldots \ldots \ldots \ldots \ldots \ldots \ldots \ldots$

3. REVISÃo DE LITERATURA $\ldots \ldots \ldots \ldots \ldots \ldots \ldots \ldots$

4. MAterial e mEtodos $\ldots \ldots \ldots \ldots \ldots \ldots \ldots \ldots \ldots \ldots$

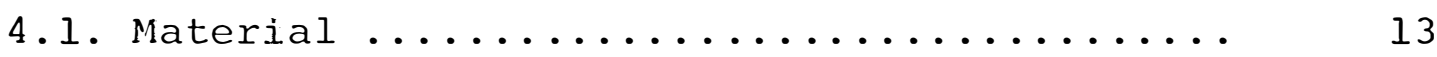

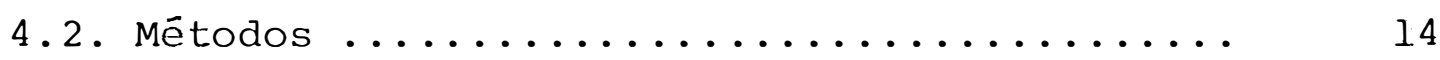

4.2.1. Polpas produzidas em laboratório ... 14

4.2.2. Polpas comerciais ............ 18

4.2.3. Análises das propriedades das polpas 19

4.2.3.1. Medições das dimensões das fibras ............... 19

4.2.3.2. Preparo das folhas ....... 20

4.2.3.3. Propriedades óticas ...... 20

4.2.3.4. Propriedades físico-mecânicas 21

4.2.3.5. Propriedades químicas ..... 21

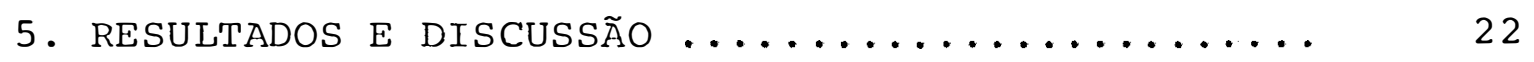

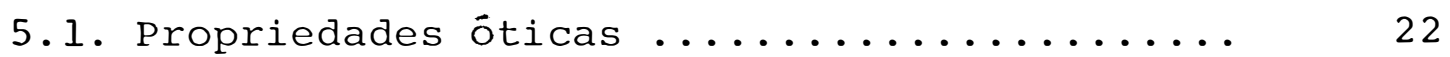

5.1.1. Propriedades das polpas conerciais de Eucalyptus grandis e composta...

5.1.2. Polpas separadas pelo classificador de fibras "Bauer McNett" ........... 
.$v i$.

5.1.3. Polpas produzidas em laboratörio ... 39

5.1.4. Polpas comerciais ............. 43

5.1.5. Análise de Regressão Linear ....... 45

5.2. Propriedades físico-mecânicas .......... 5 I

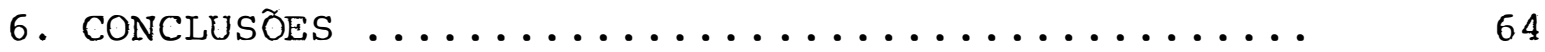

7. LiterAtura CITADA $\ldots \ldots \ldots \ldots \ldots \ldots \ldots \ldots \ldots \ldots \ldots$

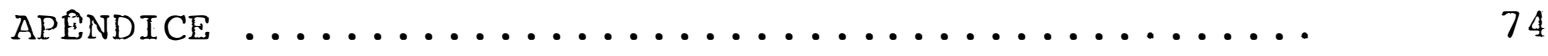




\title{
UMA NOVA ABORDAGEM PARA ANÁLISE DA OPACIDADE DO PAPEL
}

\author{
Autora : MARIA APARECIDA CARPIM \\ Orientador: Prof.Dr. LUIZ ERNESTO GEORGE BARRICHELO
}

RESUMO

Este trabalho teve como finalidade avaliar a influência do nümero de fibras por grama de polpa nas propriedades de espalhamento de luz e opacidade do papel, procu rando esclarecer como este parāmetro pode interferir na consolidação das fibras na folha de papel.

Foram utilizadas polpas produzidas de madeira de diferentes regiões da seção transversal de árvores de Eucalyptus grandis e polpas comerciais não refinadas de E. grandis, E. urophylla, E. deglupta, E. globulus, Betula verrucosa, Gmelina arborea e pinheiros tropicais.

Dentre as polpas comerciais, as quatro pri meiras, além de serem analisadas na forma original, sofreram classificação das fibras pelo "Bauer McNett", através de 
três peneiras de 30, 50 e 100 mesh, separando a polpa origịnal de cada espécie em quatro (R-30, R-50, R-100 e P-100).

Além das propriedades óticas e de resistên cia físico-mecânicas, foram determinadas as características das fibras e a composição química das polpas, para suas caracterizações.

Os resultados obtidos mostraram que polpas com maior número de fibras por grama apresentaram maior opa cidade do papel, pois continham mais interfaces fibra-ar, o que favoreceu o espalhamento da luz e a opacidade. Em relação às propriedades físico-mecâni case à resistência ao ar Gurley, ficou demonstrado que as polpas com grande quantidade de fibras produziram indices su periores de resistência à tração e ao estouro, já que possuiam mais pontos de contato e maior número de ligações. Ao mesmo tempo, se observou nessas polpas maior resistência a passagem do ar. 


\title{
A NEW APPROACH FOR THE ANALYSIS OF THE PAPER OPACITY
}

\author{
Author : MARIA APARECIDA CARPIM \\ Adviser: Prof.Dr. LUIZ ERNESTO GEORGE BARRICHELO
}

\section{SUMMARY}

The objectives of this work were to evaluate the influence of the number of fibersper gram of pulp in the properties of light scattering and opacity of a sheet of paper, and try to explain how these parameters can interfere in the consolidation of fibers in a sheet of paper with pulps obtained from wood of different transversal cross sections of trees of $E$. grandis, and from commercial pulps without refining of E. grandis, E. urophyzza, E. deglupta, E. globulus, Betula verrucosa, Gmelina arborea and tropical pine.

The first four commercial pulps described were analised in their original form and also had their fibers classified by the "Bauer McNett" through three 
sieves of 30,50 and 100 mesh, which have resulted in four fractions of pulps (called $\mathrm{R}-30, \mathrm{R}-50, \mathrm{R}-100$ and $\mathrm{P}-100$ ) for each species.These rractions were submitted to tests of optical and physical properties of the paper, and had their fibers characterized through anatomical and chemical determinations. The analysis of results indicated that pulps with the greatest number of fibersper gram showed the greatest paper opacity, because they had much more interfaces air-fiber which have increased the light scattering and opacity of the paper.

In relation to the physical properties, it $\mathrm{h}$ ad been proved that pulps with high quantities of fibers give high indices of resistance to burst and tensile, since they had more much contact points and interfiber bon.ing. At the same time, it has been observed in these pulps a greater resistance to the passing air. 


\section{INTRODUÇÃO}

Atualmente, o Brasil é o principal exportą dor mundial de celulose de fibra curta e importante fornecedor de papéis de escrita e impressão para os mercados da Africa, Âsia, América Latina e Oceania.

A crescente demanda por produtos de melhor qualidade é uma indicação da necessidade de serem desenvolví dos estudos acerca dos principais parâmetros que a condicionam. No contexto geral, a opacidade se destaca como uma das propriedade mais exigidas na fabricação de papéis de escrita e impressão.

Uma das formas usuais para melhorar esta propriedade é através do aumento da gramatura (gramas de papel por metro quadrado). Todavia esta alternativa contraria 
a tendência atual no sentido de se diminuir este parâmetro para reduzir o custo. Outras soluções como redução do grau de refinação ou aumento do teor de cargas trazem como consequências desfavoráveis a diminuição das resistências mecânicas do papel produzido.

No que se refere à matéria-prima, as carac terísticas das fibras e composição química da polpa também influenciam as propriedades do papel. Os aspectos anatômicos são considerados os mais importantes e diretamente relaciona dos com as propriedades óticas e de resistências.

Dessa maneira, se torna fundamental a compreensão das inter-relações entre características das fibras e propriedades do papel. Em particular, o estudo de novos pą râmetros, como o número de fibras por grama, deve possibilitar melhor conhecimento das caracteristicas da polpa, que po dem melhorar sua qualidade. 
.3 .

\title{
2. OBJETIVO
}

\begin{abstract}
Analisar a influência do número de fibras por grama de polpas obtidas de folhosas e coniferas e suas características sobre as propriedades de espalhamento de luz e opacidade do papel e os reflexos nas principais resistências físico-mecânicas.
\end{abstract}




\section{REVISÃO BIBL I OGRAFICA}

A estrutura do papel é constituída por vários elementos formando interfaces entre si e com o ar. Devido esse fato, a luz incidente em uma folha torna-se difusa quando parte é refletida, espalhada a diferentes ângulos e absorvida (CLARK, 1978). Os fenômenos de reflexão, espalhamento e absorção da luz são responsáveis pela alvura e opací dade do papel.

O método convencional utilizado para avaliação dessas propriedades óticas é baseado na teoria do espalhamento da luz desenvolvida por Kubelka e Munk em 1931.Es ta teoria foi modificada em trabalhos posteriores, sendo ain da sumarizada em trabalhos mais recentes (HILLEND, 1966; ROBINSON, 1975 e SCALLAN, 1985). 
A teoria de Kubelka e Munk considera a foTha de papel como uma fina camäda formada por um grande nú mero de pequenos elementos, cada um contribuindo para reflexão e diluição da luz que incide sobre a folha, proporcionan do o espalhamento e absorção. Pela utilização das equações que governam esses processos elementares, Kubelka e Munk derivaram outras que podem estimar os coeficientes de espalhamento (s) e absorção de luz (k), a alvura e a opacidade do papel, através dos fatores de reflectância $R_{0}$ e $R^{\infty}$. O primeiro fator é obtido de uma única folha com fundo escuro e o segundo, $R \infty$, por um conjunto de folhas suficientemente opaca Desta maneira, o valor da opacidade descre ve a habilidade de uma única folha de papel em obstruir a passagem de luz e pode ser obtida através da relação $R_{0} / R_{\infty} \cdot A$ opacidade é dependente das duas constantes básicas da teoria de Kubelka e Munk, ou seja, os coeficientes de espalhamento e absorção de luz.

Para CLARK (1978), os coeficientes de espa Ihamento e absorção fornecem estimativas da capacidade da fo Iha de papel em espalhar e absorver a energia da luz.

Segundo GIERTZ (1965), o coeficiente de absorção é de secundário interesse, porque é controlado pelo processo de cozimento, grau de branqueamento e reversão da alvura. Por outro lado, o coeficiente de espalhamento é influenciado pela matéria-prima fibrosa, condições de polpação 
e maioria das operações de fabricação do papel. Todas estas variáveis podem ser alteradas e modificar outras propriedades do papel além da opacidade.

Para CASEY (1960), o coeficiente de espalhamento é proporcional à área total de superfície por unida de de massa do material, à densidade aparente e ao indice de refração e, geralmente, está ligado à estrutura do papel, fa tores também citados por ROBINSON (1976). O coeficiente de absorção, por sua vez, é proporcional ao comprimento médio do caminho atravessado pela luz que passa pelo material, à densidade aparente, ao indice de refração e dependente da na tureza química do papel. O mesmo autor afirma ainda que, uma vez que os valores dos coeficientes de espalhamento e absorção tenham sido determinados para dada polpa, pode ser assumido que esses valores permanecem constantes, a menos que mu danças sejam feitas no método de preparação da mesma.

Segundo LAW e KORAN (1981), O coeficiente de espalhamento ótico mede a quantidade de luz que se difunde pelo material. Este parâmetro fornece um indice da área de ligação das fibras, com a suposição que o aumento das ligações tornará a folha mais transparente, diminuindo assim a difusão da luz. Esta hipótese está de acordo com as observações de NORDMAN (1965) que a luz é espalhada pela superfície das fibras que não estão em contato. 
Posteriormente SCALLAN e BORCH (1972), basea dos também nos coeficientes de espalhamento e absorção, apre sentaram novo modelo teórico para interpretar a reflectância da luz na folha de papel.

Estes autores descreveram a teoria em termos de um modelo que considera a estrutura interna da folha constituída de limitado número de camadas paralelas, alterna das com ar e material sólido (camadas de celulose), sendo es te modelo mais relacionado com a morfologia do papel.

Utilizando este modelo SCALLAN e BORCH (1972, 1974 e 1976a) demonstraram que a teoria pode descrever a variação das propriedades óticas das polpas de diferen tes niveis de alvura, graus de moagem, gramatura e espécies, além de explicar o efeito da distribuição de massa no papel. Estes autores consideram que esta teoria tem algumas vantagens sobre a que foi apresentada por Kubelka-Munk. O modelo é mais próximo da real morfologia do papel do que o modelo homogêneo assumido anteriormente e as equações são derivadas de uma consideração mais realista dos processos elementares de espalhamento e absorção de luz.

Este modelo foi utilizado por HASUIKE e MURAKAMI (1985) para analisar os resultados do aumento do coeficiente de espalhamento e da opacidade do papel com a re finação das polpas de fibras de parede espessa; nesse estudo registraram também incrementos nas propriedades físico-mecâ- 
nicas do papel. Os autores concluiram que a melhoria das pro priedades óticas podia ser explicada pelo aumento do nümero de camadas oticamente ativas da teoria desenvolvida por SCAL LAN E BORCH.

Trabalho anterior apresentado por HIGGINS et alii (1973), mostrou resultados semelhantes. A partir da refinação de polpas produzidas com espécies de alta densidade foram obtidas maiores resistências físico-mecânicas do pạ pel, sem a redução de sua opacidade.

No entanto, muitos trabalhos registrados na literatura, particularmente os que avaliam seus resultados correlacionando com as características anatômicas das fi bras, têm mostrado, geralmente, que os fatores que favorecem os incrementos das resistências físico-mecânicas têm reflexos negativos nas propriedades óticas, principalmente na opa cidade do papel.

Segundo SCALLAN e BORCH (1976b) quanto mais extensivamente as fibras estão ligadas menor a eficiência da folha de papel no espalhamento da luz, sendo esta a razão primária que após o tratamento de refino a polpa ganha em re sistência à tração e em contra-partida perde em opacidade. FOELKEL et alii (1976) encontraram para as polpas de madeira juvenil maior resistência à tração e ao ar rebentamento comparadas às de madeira adulta de Pinus elliot tii, enquanto a opacidade foi menor. Os autores justificaram 
- fato pelas fibras das polpas de madeira juvenil se colapsa rem com facilidade durante a refinação e apresentarem maior capacidade de se interligarem.

KIBBLEWHITE (1979) estudou amostras de papel branco para impressão "off-set" com alta e baixa opacida de para determinar se as diferenças nas mesmas poderiam estar relacionadas com as características das fibras e com a proporção, distribuição e conteúdo das cargas. Através de técni cas de microscopia quantitativa, o autor observou que papéis com baixa opacidade foram consolidados e continham fibras mais colapsadas e unidas do que papéis com alta opacidade.. Concluiu que esta propriedade sofreu uma queda devido à dimi nuição do coeficiente de espalhamento, causado pelo aumento das ligações entre fibras. A média e a distribuição do diāme tro e do comprimento das fibras foram similares para ambos os papéis.

NICHOLLS e JAMIESON (1976) estudaram polpas produzidas com lenho primaveril e outonal. Comparando o papel produzido com estas polpas, de mesma densidade aparente, encontraram alto coeficiente de espalhamento e baixa resistência à tração para as polpas do lenho primaveril.

Para COLLey (1973), as fibras de paredes espessas têm pior conformabilidade lateral e as propriedades de resistência dependentes da interligação entre elas são in feriores às fibras de paredes finas. O autor concluiu que, co 
mo resultado da dificuldade das fibras se colapsarem quando secas após a refinação, papéis feitos com fibras de paredes espessas possuem maior volume especifico e rigidez e em geral, maior opacidade do que aqueles com fibras de paredes delgadas.

Segundo DINWOODIE (1965), o aumento da mé dia da espessura da parede e, por consequência, do volume es pecífico, a inclusão de fibras mais curtas e a adição de car gas resulta num aumento da opacidade do papel.

A falta de uma teoria adequada que demon $\underline{s}$ tre como as caracteristicas das fibras estabelecem o arranjo estrutural no papel, esclarecendo melhor suas correlações com as propriedades óticas, proporciona muitos resultados divergentes na literatura. Assim, são citados a seguir traba lhos que, baseados em outros parâmetros, algumas vezes chega ram a conclusões contraditórias em relação às anteriormente apresentadas.

Segundo GIERTZ (1965), as grandes diferenças na opacidade entre vários tipos de papel são primariamen te causadas pelas diferenças nas quantidades de ligação fibra-a-fibra e do número de superfícies óticas de refração e de particulas de espalhamento de luz. Assim sendo, o número, a dimensão e a forma das fibras ou de outros constituintes do papel e seus indices de refração são os fatores que deter minam a quantidade de luz que será refletida, refratada e dispersa pelo papel. 
Desta maneira, também são encontrados na literatura trabalhos que, além de levarem em consideração as dimensões das fibras, analisam a quantidade de fibras presen tes na polpa.

KIBBLEWHITE (1973) estudando polpas produzidas a partir da madeira de Pinus radiata, e também UPRI CHARD (1973) trabalhando com a mesma espécie e com "douglasfir" (Pseudotsuga menziesii), encontraram nas polpas de made $\underline{i}$ ra juvenil dessas espécies, maiores coeficientes de espalhamento de luz do que na madeira adulta; esses resultados foram justificados pelo fato dessas polpas conterem maior núme ro de fibras por grama, e portanto, maior área superficial disponivel para o espalhamento da luz.

O número de fibras por grama, além de tex influência direta sobre a formação do papel, tem importāncia significativa na resposta da polpa ao tratamento de refinação e influencia a conformabilidade das fibras na folha de papel (CLAUDIO-DA-SILVA, 1983).

No trabalho apresentado por UPRICHARD (1973), observou-se também que, quando levemente refinadas, as polpas da região do cerne da madeira apresentaram baixa resistência ao rasgo, mas boa resistência à tração e à energia de tensão, além de maior opacidade. O autor concluiu que a excessiva moagem dessas polpas deve ser evitada, pois as melhores qualidades das mesmas serão perdidas. 
KIBBLEWHITE (1984) estudando as caracterís ticas das fibras e dos finos da madeira de cerne e alburno de Pinus radiata, em pastas mecânicas e termomecânicas, concluiu que as excelentes propriedades óticas obtidas para as polpas de cerne da madeira podem estar relacionadas com os efeitos de consolidação do grande número de fibras curtas e finas e dos elementos de fibras. Assim, as folhas da polpa do cerne continham muito mais interfaces fibra-ar lou elemen tos de fibra-ar) do que aquelas feitas com polpa de alburno. A redução do tamanho dos elementos constituintes do papel aumenta o número de interfaces fibra-ar, des de que esses elementos não sejam menores que $0,3 \mu \mathrm{m}$, o que os tornariam pequenos demais para a difração da luz (CLARK, 1978). UPRICHARD e GRAY (1972), estudando polpas de Pinus nigra numa mesma densidade aparente, encontraram que as polpas de madeira com 15 anéis de crescimento apresen taram maior coeficiente de espalhamento do que aquelas com 25 anéis, embora o coeficiente de espalhamento diminuisse com o aumento da densidade aparente e da ligação entre fibras. LONNBERG (1970) encontrou alta opacidade e alto coeficiente de espalhamento de luz em polpas de madeira de folhosas com casca de árvores de 3 a 5 anos de idade, atrí buindo esses resultados aos finos da casca e à grande quantí dade de fibras curtas existentes nessas polpas. 
.13.

\section{MATERIAL E MÉTODOS}

\subsection{Material}

Os materiais utilizados constituiram - se de polpas sulfato branqueadas fornecidas pelas indústrias e produzidas em laboratórí, como identificadas a seguir.

4.1.1. Polpas produzidas em laboratório

As polpas produzidas em laboratório foram obtidas a partir de madeira de Eucalyptus grandis, provenien tes de árvores matrizes com 7 anos de idade, plantadas em Lençóis Paulista, (SP), de propriedade de Duraflora Silvicul tura e Comércio Ltda. 
4.1.2. Polpas sulfato branqueadas industriais.

- Duas polpas produzidas pela Aracruz Celulose S/A, uma de E. grandis e uma mistura de 67\% E. urophyzza e 33\% de $E$. grandis. Para facilitar a compreensão do texto, a última polpa será chamada apenas de composta.

- Polpa de E. globulus produzida pela CELBI, Portugal.

- Polpa de E. deglupta produzida pela Companhia Florestal Monte Dourado (JARI), Pará.

- Polpa de betula (Betula verrucosa) produzida pela KAUKAS, Finlândia.

- Polpa de gmelina (Gmelina arborea) produzida pela Companhia Florestal Monte Dourado (JARI), Pará.

- Polpa de pinheiro tropical (Pinus earibaea var.hondurensis) produzida pela Companhia Florestal fonte Dourado (JARI), Pará.

\subsection{Métodos}

4.2.1. Polpas produzidas em laboratório Foram retirados discos a diversas alturas de 20 árvores de E. grandis (DAP, 25\%, 50\% e 75\% da altura comerciall.

Baseado em trabalhos apresentados na literatura (BRASIL, 1976; BARRICHELO et alii, 1983; CARPIM et alii, 1985), que mostraram tendência do comprimento de fibras variar na seção transversal da madeira, foram separa- 
das uma cunha de cada disco de E. grandis, e estas foram sec cionadas em duas regiões distintas, resultando as seguintes frações :

a. Correspondente a $40 \%$ da região próxima à medula (40\% da distância medula-casca).

b. Correspondente a $20 \%$ da região próxima à casca $(20 \%$ da distância casca-medula).

\section{Graficamente temos:}
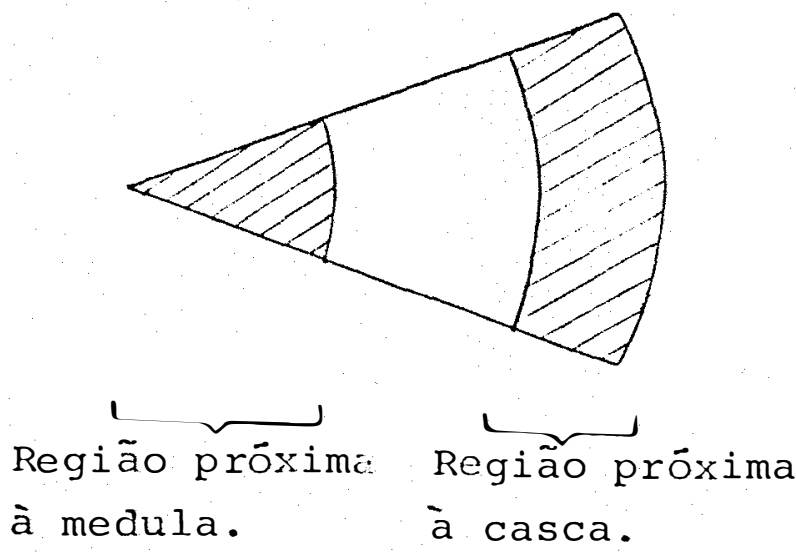

As frações correspondentes a cada região foram agrupadas e transformadas em cavacos por picagem manual e em seguida foram colocadas em cápsulas de tela de aço, que permitiram a permanēncia das mesmas separadas dentro do digestor durante o processo de cozimento. 
o cozimento foi realizado em digestor de aço inoxidável, rotativo $(2-3 \mathrm{rpm})$, de 20 litros de capací dade, aquecido eletricamente, conforme descrito por BARRICHE LO \& BRITO (1979).

Utilizando-se o processo sulfato manteve se as seguintes condições de cozimento:
a. Alcali ativo $\left(\mathrm{Na}_{2} \mathrm{O}\right)$ $=14 \%$
b. Atividade $=100 \%$
C. Sulfidez $=25 \%$
d. Relação Licor-Madeira $=4,5(\mathrm{~L} / \mathrm{kg})$
e. Temperatura máxima $=170^{\circ} \mathrm{C}$ f. Tempo até temperatura máxima $=2,0 \mathrm{~h}$. g. Tempo à temperatura máxima $=0,5 \mathrm{~h}$. Após o cozimento, as polpas foram desintegradas mecanicamente com desfibrador de disco e em seguida lavadas e depuradas.

Posteriormente, se procedeu ao branqueamen to das polpas, realizado em quatro estágios, com a sequência CEDD, onde:

$$
\begin{aligned}
& C=\text { Cloração } \\
& E=\text { Extração alcalina, } \mathrm{e} \\
& \mathrm{D}=\text { Dioxidação }
\end{aligned}
$$

As conđições pré-fixadas para cada estágio foram: 


\begin{tabular}{|c|c|c|c|}
\hline Variável & C & $\mathrm{E}$ & D \\
\hline Temperatura $\left({ }^{\circ} \mathrm{C}\right)$ & ambiente & 60 & 70 \\
\hline Tempo (minutos) & 15 & 90 & 180 \\
\hline Consistência (\%) & 3,5 & 12 & 12 \\
\hline $\mathrm{pH}$ & $1,5-2,0$ & $11,0-11,5$ & $3-4$ \\
\hline
\end{tabular}

Como o interesse principal do trabalho era estudar a opacidade do papel, procurou-se obter polpas com alvuras semelhantes.

A carga total de cloro ativo variou em fun çao do grau de deslignificação das polpas. Foi utilizado para polpa próxima à região da casca carga total de $6,5 \%$ de cloro ativo, sendo distribuido 3,5\% no estāgio da cloração, 2,0\% na primeira dioxidação e 1,0\% na segunda. A polpa de ma deira da região próxima à medula por apresentar um grau de deslignificação menor que a primeira (um número Kappa superior), recebeu na primeira dioxidação 0,5\% a mais de cloro, resultando numa carga total de cloro ativo de 7,0\%.

Além das duas polpas obtidas a partir das frações da madeira, foram feitas quatro misturas com as mesmas, totalizando-se seis amostras produzidas em laboratório. A composição das seis polpas é descrita a seguir: 
A. polpa da região próxima a casca

B. $80 \%$ polpa da região da casca e $20 \%$ polpa da região da medula

C. $60 \%$ polpa da região da casca e $40 \%$ polpa da região da medula

D. $40 \%$ polpa da região da casca e $60 \%$ polpa da região da medula

E. 20\% polpa da região da casca e $80 \%$ polpa da região da medula

F. polpa da região próxima à medula

4.2.2. Polpas comerciais

Com o objetivo de se obter polpas de uma mesma espécie com comprimento de fibras diferentes, foram se paradas as fibras de quatro polpas comerciais, a saber: Euealyptus grandis, composta, betula e pinheiro.

A separação das fibras foi realizada através do classificador "Bauer McNett", seguindo Norma SCAN-M6:69, alterando apenas o período de operação de 15 para 20 minutos; foram utilizadas peneiras de 30,50 e 100 mesh, obtendo - se das quatro espécies as seguintes polpas:

a. $R-30$

Fibras retidas na peneira mesh 30 
b. $P-30 / R-50$

Fibras que passaram pela peneira 30 mesh e foram retidas na peneira de 50 mesh

C. $P-50 / R-100$

Fibras que passaram pela peneira de 50 mesh e foram retidas na peneira de 100 mesh

d. $P-100$

Fibras que passaram pela peneira de 100 mesh.

As demais polpas comerciais ( $E$. deglupta, E. globulus e cmelina arboreal foram analisadas somente na forma original, sem separação das fibras.

4.2.3. Análises das propriedades das polpas

Foram analisadas as caracteristicas das fibras e as propriedades físicas e quimicas das polpas produ zidas em laboratório, comerciais e as separadas no Bauer McNett, conforme descrito a seguir.

\subsubsection{Medições das dimensões das fibras}

Através do analisador de fibras Kajaani FS -100, obteve-se o comprimento médio ponderado das fibras, o número de fibras por grama e a percentagem de finos (o anali sador pode ser programado para apresentar como finos as fibras, elementos ou pedaços de fibras que passam pela peneira de 200 mesh). O cálculo do "coarseness" foi baseado nos resultados fornecidos pelo mesmo analisador. 
Para determinação das dimensões transversais das fibras, preparam-se lâminas com fibras coloridas com safranina. As lâminas foram levadas ao microscópio ótico e com auxilio de ocular micrométrica, mediu-se na metade do comprimento das fibras, os diâmetros externos e internos, a partir dos quais se calculou a espessura da parede celular. Foram medidas aproximadamente 50 fibras de cada polpa.

\subsubsection{Preparo das folhas}

A formação e a preparação das folhas para testes foram de acordo com as Normas SCAN-C26:76, SCAN-M5:76. As condições de condicionamento obedeceram Norma SCAN-P2:75.

\subsubsection{Propriedades óticas}

a. Opacidade (Norma SCAN-P 8:75)

b. Coeficiente de Espalhamento de Luz (Norma SCAN-C 27:69) OBS.: O coeficiente de absorção foi calculado através da equação de Kubelka e Munk, que é descrita a seguir:

$$
\mathrm{k} / \mathrm{s}=\left[1-\mathrm{R}^{\infty}\right]^{2} / 2 \mathrm{R}^{\infty}
$$

onde: $k=$ coeficiente de absorção de luz 
$\mathrm{s} \quad=$ coeficiente de espalhamento de luz

$\mathrm{R}_{\infty}$ = reflectância de um bloco de papel espesso o suficiente para ser opaco.

\subsubsection{Propriedades físico-mecânicas}

a. Densidade aparente do papel

(Norma SCAN-P 7:75)

b. Resistência ao ar Gurley

(Norma SCAN-P 19:66)

c. Resistência à tração

(Norma SCAN-P 44:81)

d. Resistência ao estouro

(Norma SCAN-P 25:68)

e. Resistência ao rasgo

(Norma SCAN-P 11:73)

4.2.3.5. Propriedades químicas

a. Teor de pentosanas (TAPPI-T $233 \mathrm{ts}-63$ )

b. Teor de extrativos em etanol-tolueno e em diclorometano (TAPPI-T 204 os-76) (utilizando o tolueno em substituição ao benzeno, segundo recomendação de GOETZLER, 1982).

c. Teor de cinzas (TAPPI-T $211 \mathrm{~m} 58$ ). 


\section{RESULTADOS E DISCUSSAOO}

\subsection{Propriedades Oticas}

5.1.1. Propriedades das polpas comerciais ce E. grandis e composta

Na análise de polpas celulósicas, normalmente o estudo da densidade básica da madeira, da composição quimica e das caracteristicas anatômicas dessas polpas costụ mam responder pela maioria de suas propriedades. Entretanto, em alguns casos, certos fenômenos, à primeira vista, não podem ser facilmente compreendidos baseados apenas nos parâmetros normalmente utilizados.

Os resultados da análise das propriedades das polpas de $E$. grandis e composta, apresentados na Tabe la 1, constituem um bom exemplo desses casos. 
Tabela 1 - Propriedades das polpas não refinadas de E. gran dis e composta.

\begin{tabular}{lrc}
\hline \multicolumn{1}{c}{ Propriedade } & E.grandis & composta \\
\hline densidade aparente $\left(\mathrm{kg} / \mathrm{m}^{3}\right)$ & $574 \pm 2 *$ & $533 \pm 1$ \\
indice de tração $(\mathrm{kNm} / \mathrm{kg})$ & $28,6 \pm 0,5$ & $21,9 \pm 0,5$ \\
Indice de rasgo ( $\left.\mathrm{Nm}^{2} / \mathrm{kg}\right)$ & $5,8 \pm 0,4$ & $4,7 \pm 0,2$ \\
resistência ao ar Gurley (s/100 $\mathrm{ml})$ & $2,57 \pm 0,07$ & $1,31 \pm 0,06$ \\
coeficiente de espalhamento de $\operatorname{luz}\left(\mathrm{m}^{2} / \mathrm{kg}\right) 44,4 \pm 0,4$ & $40,6 \pm 0,3$ \\
opacidade (\%) & $79,1 \pm 0,2$ & $77,3 \pm 0,2$ \\
\hline
\end{tabular}

* intervalo de confiança a nível de 95\% de probabilidade.

Nota-se de modo geral, que as propriedades da polpa de E. grandis apresentaram valores superiores aos da polpa composta. os maiores resultados da densidade aparente, dos indices de tração e rasgo e da resistência ao ar da polpa de E. grandis indicam que, mesmo antes de um tra tamento mecânico, suas fibras se ajustam e conformam melhor na estrutura do papel, ou seja, o papel apresenta uma estrutura mais consolidada do que a polpa composta, o que sugere maior flexibilidade das fibras de E. grandis.

De certo modo, estes resultados poderiam ser esperados, pois a madeira de E. grandis apresenta densidade básica de $480 \mathrm{~kg} / \mathrm{m}^{3}$, enquanto OE. urophylla possui den 
sidade em torno de $530 \mathrm{~kg} / \mathrm{m}^{3 *}$. A maior densidade básica da ma deira é, geralmente em eucaliptos, decorrente de maiores prọ porções de fibras com parede mais espessas, consequentemente mais rigidas, apresentando menor conformabilidade. Assim sen do, as propriedades de resistência que dependem da interliga cão entre fibras são prejudicadas em relação àquelas polpas com fibras de paredes mais finas e flexíveis (COLLEY, 1973). Um exemplo disso pode ser observado na Figura 1, onde são mostrados dois cortes transversais de papel produzidos a partir de madeira de alta e baixa densidade de híbridos naturais de E' grandis. Nota-se que a estrutura do papel a partir da madeira menos densa $\left(449 \mathrm{~kg} / \mathrm{m}^{3}\right)$ é bem mais consolidada, com fibras fortemente ligadas, enquanto as espessas paredes das fibras do papel produzido com madeira de alta densidade $\left(608 \mathrm{~kg} / \mathrm{m}^{3}\right)$, apresenta maiores espaços entre fibras, proporcionando uma estrutura mais aberta, com vo lume específico aparente bem maior.

* Dados fornecidos pelo Centro de Pesquisas e Tecnologia da Aracruz Celulose S.A.). 


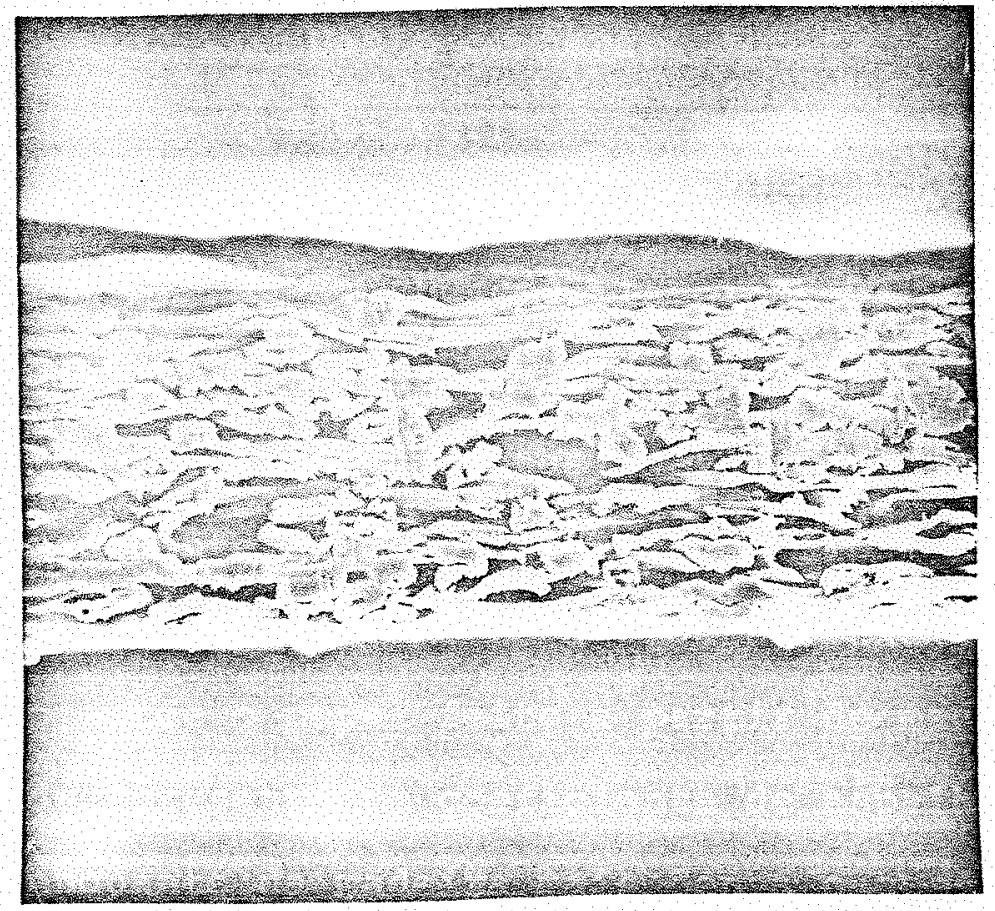

1A. densidade básica de $449 \mathrm{~kg} / \mathrm{m}^{3}$ (ampliação 400X)

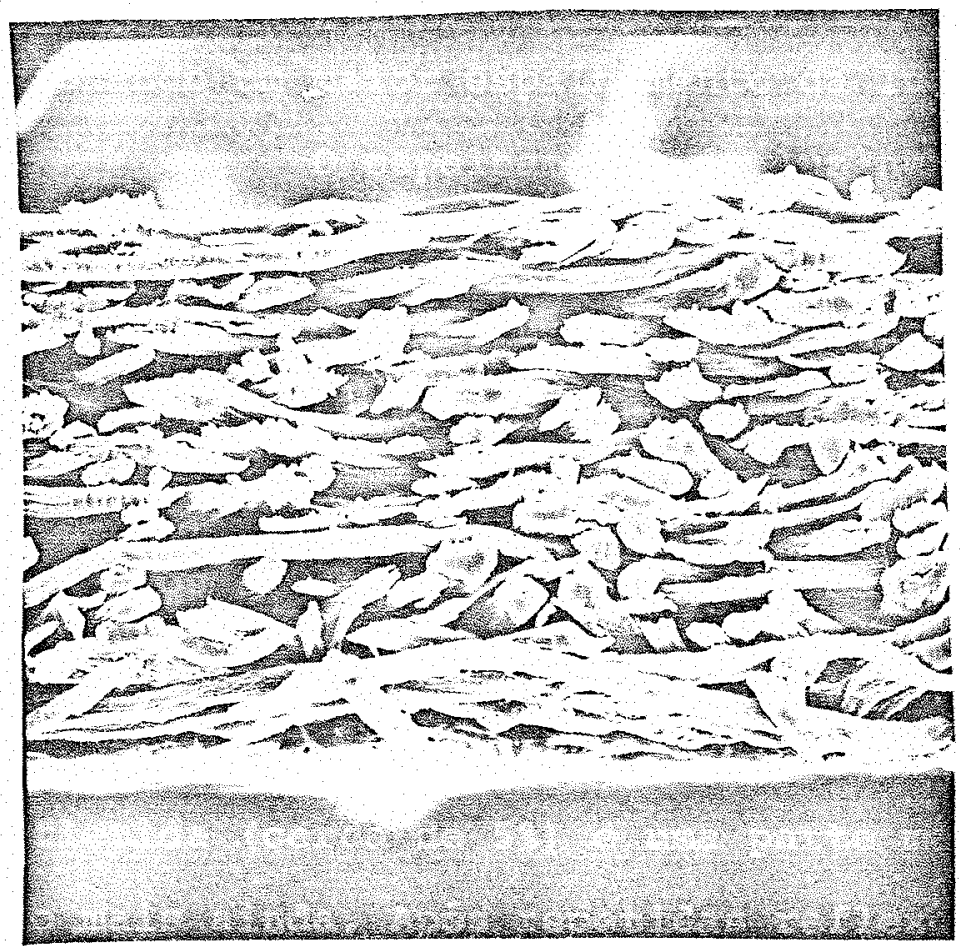

1B. densidade básica de $608 \mathrm{~kg} / \mathrm{m}^{3}$ (ampliação 400X)

Figura 1 - Fotos de cortes transversais do papel produzidos a partir de madeira de $E$. grandis de baixa e alta densidade básica (fotos cedidas pelo Centro de Pesquisas e Tecnologia da Aracruz Celulose S.A.). 
Neste contexto, foi de certo modo surpreen dente observar que o coeficiente de espalhamento e a opacida de da polpa composta também mostraram menores valores do que a polpa de $E$. grandis. Isto porque era de se esperar que papéis com estruturas mais consolidadas e compactas fossem também mais transparentes, devido à menor refração da luz, consequente de menos interfaces fibra-ar.

Novamente a Figura 1 exemplifica bem este conceito, onde o papel feito a partir de madeira de baixa densidade apresenta um coeficiente de espalhamento de 40,9 $\mathrm{m}^{2} / \mathrm{kg}$, enquanto da madeira mais densa o coeficiente de espalhamento de luz do papel é de $45,8 \mathrm{~m}^{2} / \mathrm{kg}$, pois este apresenta uma estrutura mais aberta, com mais espaços entre fibras, proporcionando um maior espalhamento da luz.

o espalhamento da luz num corpo oticamente heterogêneo como o papel depende das suas superficies de refração de luz. Utilizando uma figura esquemática, reproduzida neste trabalho na Figura 2, GIERTz (1965) expõe que no pa pel a luz incidente, mesmo se orientada, irá incidir nos vários elementos de superfície em todos os ângulos possiveis e se espaḷará difusamente. no interior do corpo ótico. Em cada su perficie ótica a luz incidente se divide, sendo uma porção mí nima refletida (cerca de 5\%) e uma parte maior refratada, pe netrando mais ainda. Após repetidas reflexões e refrações, parte da luz incidente irá retornar à superfície original e 
deixará o corpo, enquanto outra parte irá passar através des te e sairá pelo lado oposto.

Desse modo, quanto mais superfícies óticas de refração estiverem presentes no papel, mais fácil será pa ra a luz incidente ser refratada de volta à superfície original e menor será a luz que irá alcançar o lado oposto, sain do como luz transmitida.

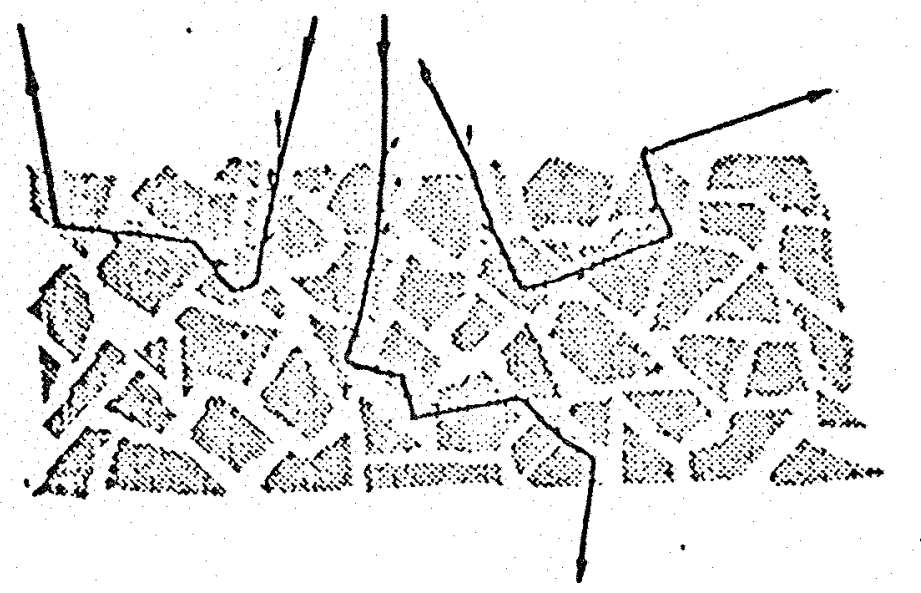

Figura 2 - Representação esquemática do espalhamento da luz num corpo com partículas de formas irregulares (GIERTZ， 1965) .

Baseado nesta descrição, hoje amplamente difundida e aceita, a qual destaca a importância da quantida de de superfícies óticas de refração quando a luz atravessa uma folha de papel, pode-se também analisar a propriedade de opacidade do papel em termos de outro parâmetro importante 
da polpa, ou seja, o número de fibras por grama, o qual tem recentemente despertado grande interesse.

A análise desta propriedade indicou, como è observado na Tabela 2, que o E. grándis apresenta um número de fibras por grama bastante superior à polpa composta. Com maior número de partículas, a luz pode sofrer mais refra ções e reflexões, pois é obrigada a atravessar mais interfaces fibra-ar, o que aumenta a sua dispersão. Neste caso, o coeficiente de espalhamento e a opacidade do papel poderiam também aumentar, apesar da maior consolidação da folha de $E$. grondis . Esta foi uma hipótese extensivamente testada neste estudo.

Tabela 2 - Características anatômicas das polpas de E. grandis e composta (determinados pelo analisador de fibras Kajaani FS-100).

\begin{tabular}{lcc}
\hline Polpa & E. grandis & Composta \\
\hline comprimento médio de fibra (mm) & 0,65 & 0,68 \\
número de fibras/g (milhões) & 23,6 & 18,9 \\
"coarseness" (mg/100m) & 7,9 & 9,5 \\
\hline
\end{tabular}

Resultados interessantes foram apresentados por CIAUDIO-DA-SILVA (1981) ao analisar polpas de $E$. 
grandis e E. rostrata, que possuiam diferentes nümeros de $\mathrm{f} \underline{\underline{i}}$ bras por grama. A primeira polpa apresentou 14,7 milhões de fibras por grama e a polpa de $E$. rostrata possuia $18,5 \mathrm{mi}-$ Ihões (medições baseadas em outro tipó de técnica). A Figura 3 mostra o corte transversal do papel dessas duas polpas. № ta-se que a folha do papel de E. rostrata, devido ao maior número de fibras, apresenta muito mais interfaces fibra-ar,o que levou a maior difração da luz, e consequentemente, o coe ficiente de espalhamento da polpa de $E$. rostrata foi de 52,0 $\mathrm{m}^{2} / \mathrm{kg}$, enquanto para $\circ E$. grandis foi de $48,6 \mathrm{~m}^{2} / \mathrm{kg}$. 


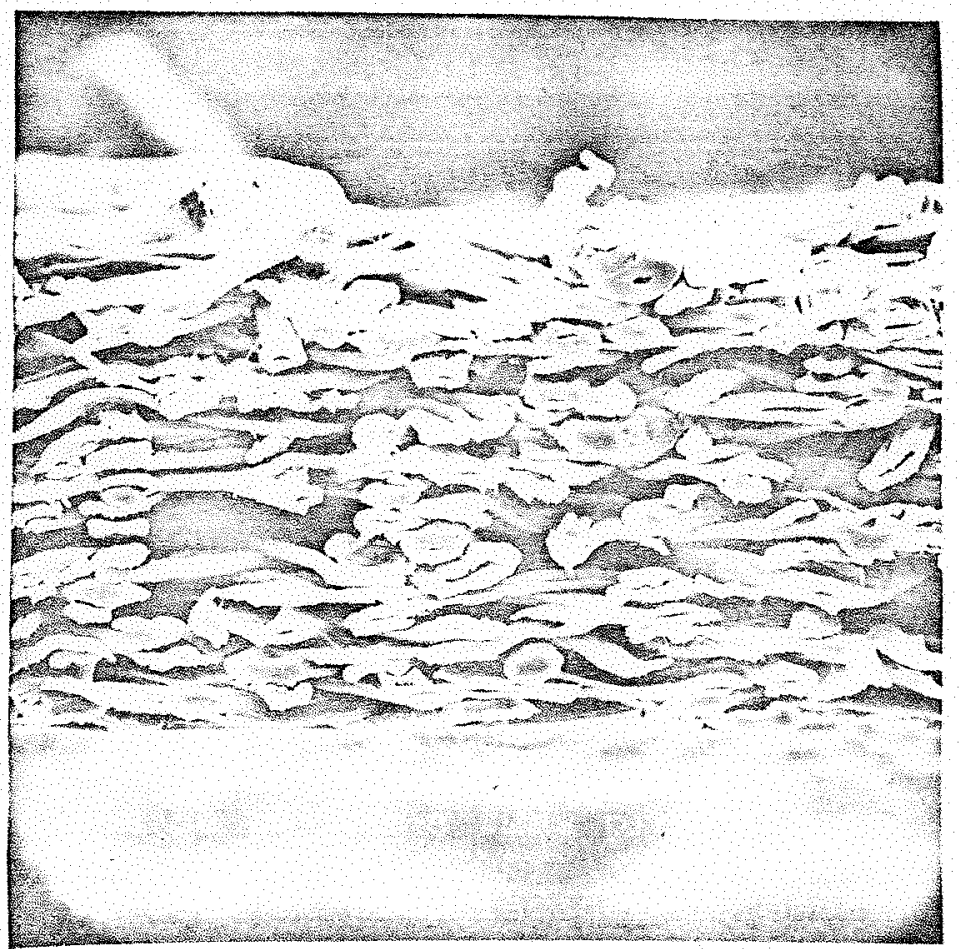

3A.E. grandis

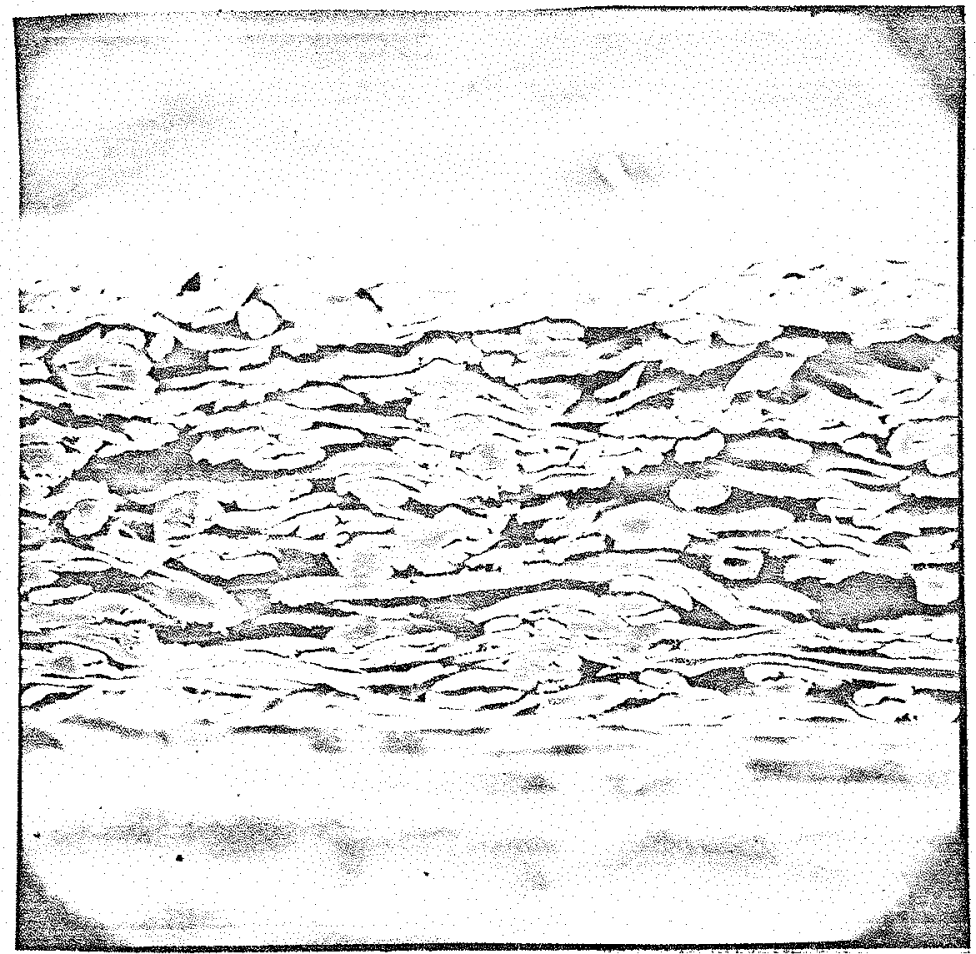

3B. E. rostrata

Figura 3 - Cortes transversais de papel (ampliação 400X) (CIAUDIO-DA-SILVA, 1981) 
Dessa maneira, as propostas anteriores somente baseadas em aspectos relativos à flexibilidade de fibras e consolidaçäo do papel, não foram satisfatórias para explicar o comportamento das polpas de E. grandis e comoosta em relação ao coeficiente de espalhamento e à opacidade. Como o número de fibras por grama parece ser também um parâmetro importante para o arranjo estrutural das fibras no papel, este foi extensamente analisado neste trabalho, dentre os vários parâmetros anatômicos. Foram estudados diversos tipos de polpas e suas propriedades, sendo que maior ênfase foi dada às propriedades de espalhamento de luz e opací dade do papel.

5.1.2. Polpas separadas pelo classificador de fibras "Bauer McNett"

Com interesse de buscar uma avaliação mais abrangente das influências das caracteristicas das fibras nas propriedades do papel, as polpas de E. grandis e con-posta foram separadas pelo classificador de fibras "Bauer McNett", afim de se obter, para a mesma espécie, frações das polpas com caracteristicas morfológicas diferentes.

Foram classificadas também pelo "Bauer McNett", polpas de betula e de pinheiro, que possuen caracteristicas de fibras bem distintas das polpas de eucalipto. 
Desse modo, a discussão da influência das caracteristicas das fibras abrange uma ampla faixa de variáveis anatômicas como pode ser observado nas Tabelas 3 a 5 .

Tabela 3 - Comprimento rédio de fibra (mm) das polpas separa das no "Bauer McNett".

\begin{tabular}{|c|c|c|c|c|}
\hline & E. grandis & Composta & Betula & Pinheiro \\
\hline$R-30$ & 0,82 * & 0,82 & 1,04 & 3,02 \\
\hline$P-30 / R-50$ & 0,68 & 0,75 & 0,87 & 1,43 \\
\hline$P-50 / R-100$ & 0,60 & 0,60 & 0,66 & 0,91 \\
\hline$P-100$ & 0,45 & 0,44 & 0,54 & 0,58 \\
\hline
\end{tabular}

* repetições não exibem diferenças significativas a nível de 95\% de probabilidade

Tabela 4 - Diâmetro da fibra $(\mu \mathrm{m})$ das polpas separadas no no"Bauer McNett".

\begin{tabular}{lllll}
\hline & $E$. grandis & Composta & Betula & Pinheiro \\
\hline R-30 & $22,02 \pm 0,52 *$ & $21,19 \pm 0,94$ & $32,77 \pm 1,41$ & $49,13 \pm 2,25$ \\
P-30/R-50 & $21,37 \pm 0,62$ & $20,56 \pm 0,85$ & $31,19 \pm 1,26$ & $50,68 \pm 2,43$ \\
P-50/R-100 & $20,30 \pm 0,83$ & $20,07 \pm 0,71$ & $29,29 \pm 1,42$ & $49,32 \pm 2,50$ \\
P-100 & $19,34 \pm 1,09$ & $21,00 \pm 1,33$ & $29,20 \pm 1,43$ & $47,10 \pm 2,34$ \\
\hline
\end{tabular}

* intervalo de confiança à nível de 95\% de probabilidade 
Tabela 5. - Espessura da parede celular $(\mu \mathrm{m})$ das polpas separadas no"Bauer McNett".

\begin{tabular}{lccll}
\hline & E. grandis & Composta & Betula & Pinheiro \\
\hline $\mathrm{R}-30$ & $5,67 \pm 0,23 *$ & $5,81 \pm 0,30$ & $6,83 \pm 0,46$ & $9,82 \pm 0,57$ \\
$\mathrm{P}-30 / \mathrm{R}-50$ & $5,49 \pm 0,13$ & $5,41 \pm 0,29$ & $6,40 \pm 0,34$ & $8,44 \pm 0,60$ \\
$\mathrm{P}-50 / \mathrm{R}-100$ & $4,94 \pm 0,28$ & $5,14 \pm_{0,33}$ & $5,88 \pm 0,31$ & $7,70 \pm 0,60$ \\
$\mathrm{P}-100$ & $4,88 \pm 0,27$ & $5,46 \pm 0,28$ & $6,04 \pm 0,34$ & $7,47 \pm 0,63$ \\
\hline
\end{tabular}

* intervalo de confiança à nível de 95\% de probabilidade

Como é conhecido, o classificador "Bauer

McNett" separa as fibras pelo seu comprimento. Assim, os resultados da Tabela 3 apresentam as polpas das quatro espécies estudadas, separadas em quatro frações distintas de com primento de fibra, mostrando-se decrescentes de $\mathrm{R}-30$ para $\mathrm{P}-$ 100 .

Conforme descrito anteriormente no capitu lo 4.2.3.1., o comprimento médio de fibras foi determinado no analisa dor de fibras Kajaani. Este aparelho mede todos os elementos constituintes da polpa (excetuando-se os finos); por isso geralmente se obtém valores menores do que os determinados por processos tradicionais de projeção, onde somente as fibras inteiras são analisadas. O resultado do comprimento médio de fibras é fornecido pelo próprio aparelho, calculado através da média ponderada por classe de comprimento. 
O diâmetro e a espessura da parede das fí bras também apresentaram tendência de decrescer da polpa R30 para P-100, acompanhando o comprimento de fibras.

Cabe ressaltar, que as medidas do diâmetro e da espessura de fibras apresentadas neste trabalho foram feitas no ponto central das fibras das polpas, medidas diretamente no microscópio com auxilio da ocular micrométrica. Por isso apresentam valores bem maiores dos trabalhos normalmente encontrados na literatura, que utilizam métodos alternativos para a determinação dessas dimensões. Desta maneira, esses valores serão utilizados somente para comparação entre as polpas deste trabalho, não sendo necessariamente representativos das espécies estudadas.

As demais caracteristicas das fibras das polpas estudadas, o número de fibras por grama e "coarseness" são apresentados nas Tabelas 6 e 7. O número de fibras por grama mostrou-se crescente das frações $R-30$ para $P-100$. Como se trata de um parâmetro que reflete a quantidade de fibras por unidade de peso, é natural que com a diminuição das dimensões das fibras (comprimento, diâmetro e espessura da parede) o número de fibras por grama aumentasse. Isto teve grande reflexo nas propriedades dessas polpas, conforme será discutido mais à frente. 
Tabela 6 - Número de fibras por grama (milhões) das polpas separadas no "Bauer McNett".

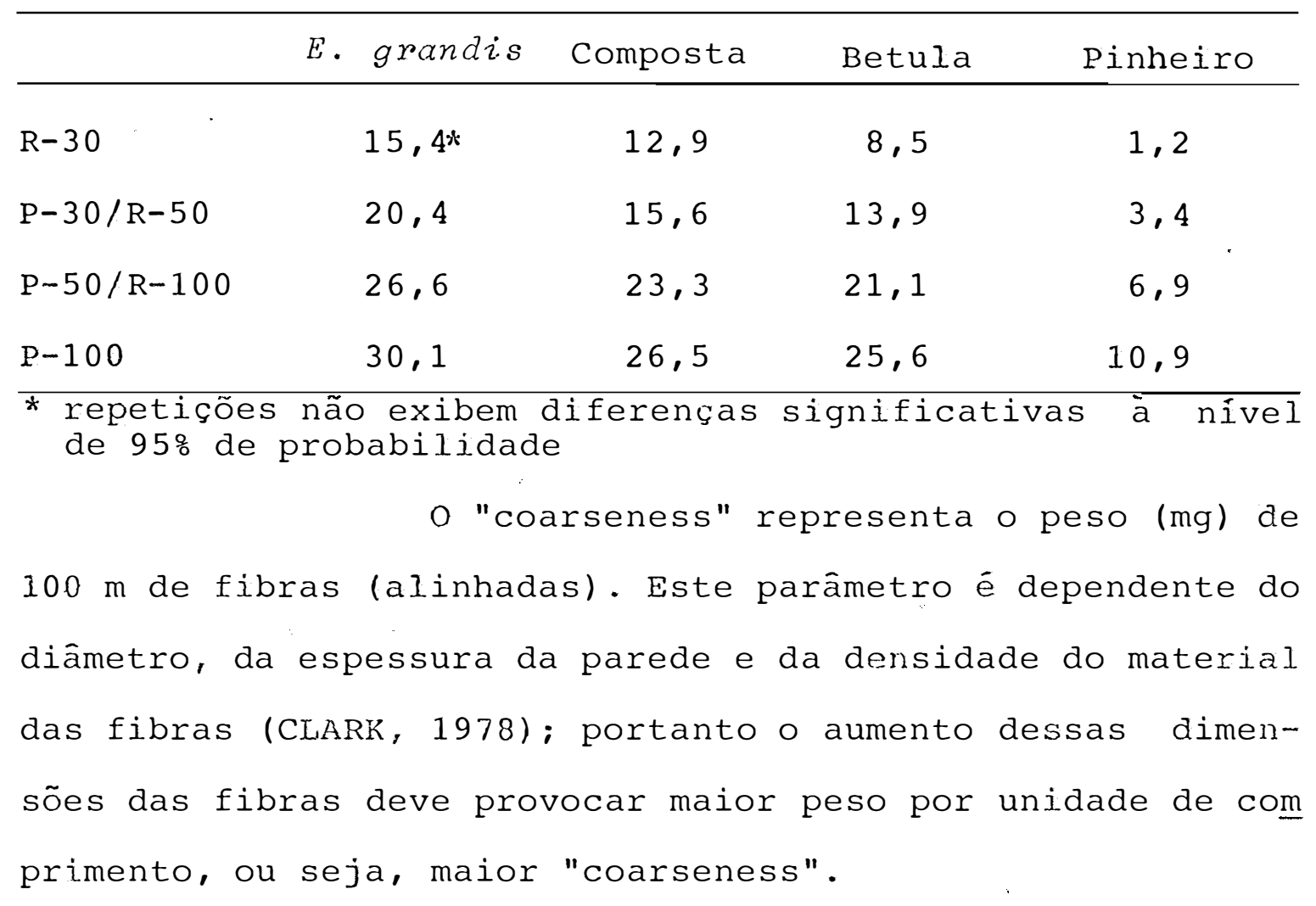

Tabela 7 - "Coarseness" (mg/100m) das polpas separadas no "Bauer McNett".

\begin{tabular}{|c|c|c|c|c|}
\hline & E. grandis & Composta & Betula & Pinheiro \\
\hline$R-30$ & 9,1 * & 10,3 & 12,6 & 34,8 \\
\hline $\mathrm{P}-30 / \mathrm{R}-50$ & 8,3 & 9,5 & 9,2 & 24,3 \\
\hline $\mathrm{P}-50 / \mathrm{R}-100$ & 7,5 & 8,3 & 8,5 & 20,2 \\
\hline $\mathrm{p}-100$ & 11,4 & 11,9 & 9,8 & 26,7 \\
\hline
\end{tabular}


Dessa maneira, é fácil se entender a diminuição do "coarseness" da polpa R-30 para R-100, uma vez que as dimensões das fibras também diminuiram neste sentido. Porém, as frações P-100 das quatro espécies estudadas apresentaram elevação no valor do "coarseness", sendo que para betula e pinheiroo "coarseness" dessas frações só não superaram as frações R-30. Uma das prováveis explicações para o fato pode estar no alto teor de cinzas das frações P-100lTa bela 25, apresentada no Apēndice).

Nas Tabelas 8 a 10 são apresentados os resultados das propriedades óticas das polpas separadas no "Bauer McNett".

Tabela 8 - Coeficiente de espalhamento de $\operatorname{luz}\left(\mathrm{m}^{2} / \mathrm{kg}\right)$ das polpas separadas no "Bauer McNett".

\begin{tabular}{lcccc}
\hline & E. grandis & Composta & Betula & Pinheiro \\
\hline $\mathrm{R}-30$ & $39,5 \pm 0,6 *$ & $34,9 \pm 0,4$ & $34,2 \pm 0,6$ & $28,5 \pm 0,6$ \\
$\mathrm{P}-30 / \mathrm{R}-50$ & $41,7 \pm 0,6$ & $36,3 \pm 0,7$ & $38,0 \pm 0,5$ & $35,1 \pm 0,6$ \\
$\mathrm{P}-50 / \mathrm{R}-100$ & $45,4 \pm 0,4$ & $41,1 \pm 0,5$ & $43,1 \pm 0,3$ & $39,1 \pm 0,3$ \\
$\mathrm{P}-100$ & $48,6 \pm 0,3$ & $45,4 \pm 0,5$ & $48,7 \pm 0,4$ & $41,6 \pm 0,8$ \\
\hline
\end{tabular}

* intervalo de confiança à nível de 95\% de probabilidade 
Tabela 9 - Opacidade $(\%)$ das polpas separadas no"Bauer MCNett".

\begin{tabular}{lcccc}
\hline & E. grandis & Comoosta & Betula & Pinheiro \\
\hline R-30 & $77,4 \pm 0,3 *$ & $75,7 \pm 0,2$ & $75,9 \pm 0,2$ & $70,5 \pm 0,3$ \\
P-30/R-50 & $78,8 \pm 0,3$ & $76,1 \pm 0,4$ & $77,4 \pm 0,2$ & $76,1 \pm 0,1$ \\
P-50/R-100 & $80,8 \pm 0,2$ & $79,6 \pm 0,3$ & $80,9 \pm 0,2$ & $79,6 \pm 0,2$ \\
P-100 & $87,1 \pm 0,1$ & $85,8 \pm 0,2$ & $89,3 \pm 0,1$ & $91,2 \pm 0,6$ \\
\hline *intervalo de confiança à nível de $95:$ de probabilidade
\end{tabular}

Tabela 10 - Coeficiente de absorção de $l u z\left(\mathrm{~m}^{2} / \mathrm{kg}\right)$ das polpas separadas no"Bauer MCNett".

\begin{tabular}{lcccc}
\hline & E. grandis & Composta & Betula & Pinheiro \\
\hline R-30 & $0,14 *$ & 0,18 & 0,20 & 0,15 \\
P-30/R-50 & 0,14 & 0,14 & 0,18 & 0,22 \\
P-50/R-100 & 0,16 & 0,19 & 0,21 & 0,29 \\
P-100 & 0,71 & 0,68 & 0,68 & 1,61 \\
* repetições não exibem diferenças significativas à nível \\
de 958 de probabilidade \\
Observa-se que o coeficiente de espalha- \\
mento de luz e consequentemente a opacidade, aumentaram par \\
tindo-se da polpa R-30 para P-100, nos quatro casos estuda- \\
dos.
\end{tabular}


Neste sentido também se aumentou o número de fibras por grama; com acréscimo de mais elementos às polpas gerou-se mais espaços intercelulares e interfaces fibra-ar nas folhas de papel. Como o espalhamento da luz ocorre nas interfaces de dois materiais com diferentes indi ces de refração (NORDMAN, 1970), o maior número de espaços inter-celulares forçou a luz a atravessar mais interfaces fibra-ar, aumentando assim a sua dispersão.

Outro parâmetro que deve ser lembrado é a ārea de superficie das fibras, uma vez que o coeficiente de espalhamento é função linear da superfície por unidade de massa do papel (CASEY, 1960), e um alto coeficiente de espalhamento pode ser esperado das fibras com grande área de exposição em relação ao seu peso (NORDMAN, 1970). Assim, o maior número de elementos aumentou a área superficial interna das folhas, favorecendo o espalhamento da luz.

Outros processos, como o refino, também produzem maior área de exposição das fibras, mas a área de contato e ligação entre fibras também aumenta, devido à maior flexibilização (um dos principais efeitos do refino), o que vem a reduzir a opacidade. Consequentemente, os resul tados apresentados na literatura após tratamento de refino das polpas, mostram o aumento da densidade aparente do papel, com a diminuição da opacidade, como resultado do aumen to das ligações entre fibras. 
Portanto, o aumento do número de fibras por grama deve ter sido essencial para elevar o coeficiente de espalhamento de luz e a opacidade, pois forneceu maior número de interfaces fibra-ar e aumentou a área de exposicão das partículas que compõem o papel e que não estão em contato mecânico.

\subsubsection{Polpas produzidas em laboratório}

O mesmo comportamento observado nas polpas separadas pelo "Bauer MCNett" foi encontrado nos testes realizados em polpas especiais produzidas em laboratório. Fo ram analisadas misturas de polpas de diversos comprimentos de fibras, produzidas a partir de madeira de E. grandis da região próxima à medula e próxima à casca. 


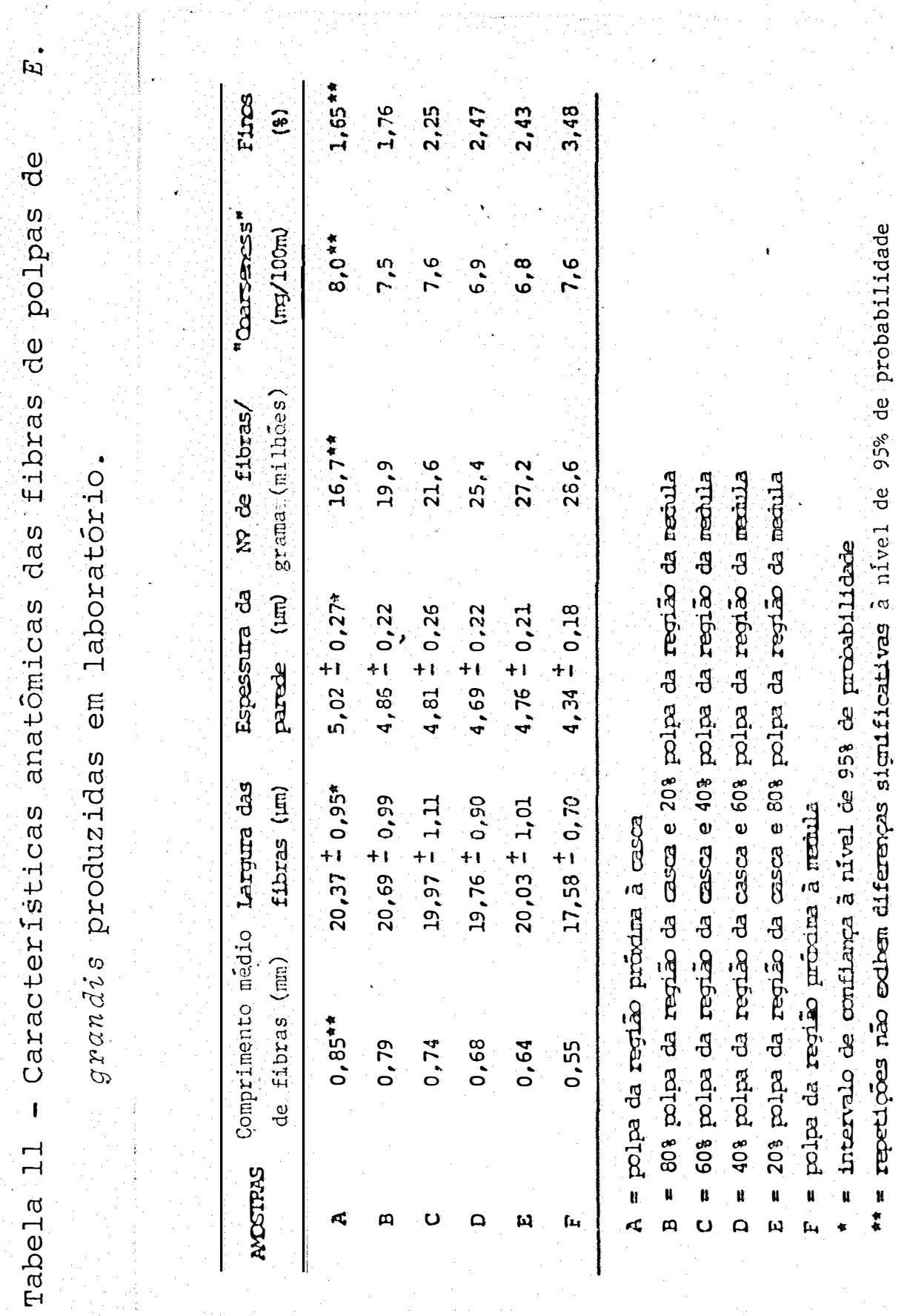


Tabela 12 - Propriedades óticas das polpas produzidas em la boratório de E. grandis.

\begin{tabular}{cccc}
\hline AMOSTRAS & $\begin{array}{c}\text { Coeficiente de } \\
\text { espalhamento de } \\
1 \mathrm{uz}\left(\mathrm{m}^{2} / \mathrm{kg}\right)\end{array}$ & $\begin{array}{c}\text { Coeficiente de } \\
\text { absorção de } \\
1 \mathrm{uz}\left(\mathrm{m}^{2} / \mathrm{kg}\right)\end{array}$ & $\begin{array}{c}\text { Opacidade } \\
(\%)\end{array}$ \\
\hline A & $38,5 \pm 0,5 *$ & $0,21 * *$ & $78,4 \pm 0,3 *$ \\
B & $39,1 \pm 0,4$ & 0,22 & $79,3 \pm 0,2$ \\
C & $41,4 \pm 0,3$ & 0,23 & $80,0 \pm 0,1$ \\
D & $42,7 \pm 0,6$ & 0,23 & $80,5 \pm 0,1$ \\
E & $44,0 \pm 0,3$ & 0,25 & $81,0 \pm 0,1$ \\
F & $45,1 \pm 0,2$ & 0,25 & $81,5 \pm 0,1$ \\
\hline
\end{tabular}

$A=$ polpa da região próxima à casca

$\mathrm{B}=80 \%$ polpa da região da casca e $20 \%$ pol.pa da região da medula

$C=60 \%$ polpa da região da casca e $40 \%$ polpa da região da medula

$D=40 \%$ polpa da região da casca e $60 \%$ polpa da região da medula

$\mathrm{E}=20 \%$ polpa da região da casca e $80 \%$ polpa da região da medula

$F=$ polpa da região próxima a medula

* = intervalo de confiança à nível de 95\% de probabilidade

* * = repetições não exibem diferenças siạnificativas à nível de $95 \%$ de probabilidade 
A medida que se aumentou a proporção de polpa da medula, acrescentando fibras mais curtas à polpa,o número de fibras por grama e a percentagem de finos primários (que acompanham a polpa antes do tratamento mecânico de refinol aumentaram, como pode ser observado na Tabela 11, o que proporcionou mais partículas à constituição das foThas de papel, gerando mais interfaces fibra-ar. Como conse quência, o coeficiente de espalhamento e a opacidade (Tabela 12) aumentaram, pois a ação de difusão da luz pelas partículas (fibras ou elementos de fibra) aumenta com o número de suas interfaces com 0 ar.

Resultados semelhantes foram apresentados por UPRICHARD (1973), encontrando para as polpas de madeira juvenil maior coeficiente de espalhamento comparadas às de madeira adulta de Pinus radiata e pseudotsuga menziesii. Concluiu que as primeiras possuem fibras de paredes mais finas e as folhas de papel contêm maior número de fibras por unidade de área (ou de massa); assim as polpas de madeira juvenil têm mais superfícies disponiveis para o espalhamento da luz.

Portanto, as adições proporcionais de polpa da medula, que apresentam fibras mais curtas e finas, forneceram maior número de fibras por grama, resultando num acréscimo de partículas, o que gerou maior nümero de interfaces fibras-ar, aumentando o espalhamento da luz e a opací dade do pape?. 
5.i.4. Polpas comerciais

Com objetivo de confirmar o fenômeno observado nas polpas estudadas anteriormente, foram também analisadas diversas polpas comerciais com caracteristicas anatômicas bem distintas, relacionando-as com as propriedades óticas do papel.

Tabela 13 - Características anatômicas de fibras das polpas comerciais.

\begin{tabular}{|c|c|c|c|c|c|c|}
\hline POLPAS & $\begin{array}{l}\text { Comprimento médio } \\
\text { de fibras (mm) }\end{array}$ & $\begin{array}{l}\text { Largura da } \\
\text { flbra (Im) }\end{array}$ & $\begin{array}{l}\text { Espressura da } \\
\text { parede (Im) }\end{array}$ & $\begin{array}{l}\text { "Oourseness" } \\
(\mathrm{mg} / 100 \mathrm{~m})\end{array}$ & $\begin{array}{c}\text { in de flbras } / g \\
\text { mithoes }\end{array}$ & $\begin{array}{c}\text { Finos } \\
(\%)\end{array}$ \\
\hline E. grandis & $0,65 * *$ & $20,66 \pm 0,93^{*}$ & $5.06 \pm 0.49 *$ & $7,9 * 0$ & $23,3^{*} *$ & 4,6 \\
\hline Composta & 0.68 & $20,92 \pm 1,02$ & $5,33 \pm 0,29$ & 9.9 & 17,8 & 4,0 \\
\hline E. globulus & 0,69 & $23,02 \pm 1,08$ & $5,76 \pm 0.27$ & 8,6 & 19,8 & 3,6 \\
\hline E. deglupta & 0,63 & $23,19 \pm 1,19$ & $4,90 \pm 0,20$ & 8,3 & 22,9 & 4,9 \\
\hline Betula verrucosa & 0,81 & $27,80 \pm 1,43$ & $5,87 \pm 0,15$ & 9,6 & 15,5 & 4,2 \\
\hline Onelina arborra & 0.77 & $29,38 \pm 1,46$ & $5,86 \pm 0,33$ & 12,1 & 14.4 & 5,2 \\
\hline Pinheiro & 2,64 & $50,28 \pm 3,08$ & $8.91 \pm 1,15$ & 29.3 & 2.2 & 5,1 \\
\hline
\end{tabular}

* intervalo de confiança à nível de $95 \%$ de probabilidade

** repetições não exibem diferenças significativas à nível de $95 \%$ de probabilidade.

Nota-se através da Tabela 13, que as pol pas de eucaliptos exibiram os maiores números de fibras por grama, já que as fibras de eucalipto são mais curtas e finas, enquanto a polpa de pinheiros possui comprimento de fi bra e espessura de parede superiores às demais, o que também gera maior peso por unidade de comprimento, e portanto, maior "coarseness". 
Em relação às propriedades óticas, apresentadas na Tabela 14, verifica-se que entre as quatro espẹ cies que mostraram maior opacidade (E. deglupta, Gmelina ar borea, E. grandis e $E$. globulus) encontram-se as três espécies que também apresentaram maior número de fibras por grâ ma (E. grandis, E. deglupta, E. globulus), comprovando a in fluência deste parâmetro nas propriedades óticas do papel.

Tabela 14 - Propriedades óticas das polpas comerciais.

\begin{tabular}{lccc} 
Polpis & $\begin{array}{c}\text { Coeficiente de } \\
\text { espalhamento de luz } \\
\left(\mathrm{m}^{2} / \mathrm{kg}\right)\end{array}$ & $\begin{array}{c}\text { Coeficiente de } \\
\text { absorçāo de luz } \\
\left(\mathrm{m}^{2} / \mathrm{kg}\right)\end{array}$ & $\begin{array}{c}\text { Opacidade } \\
(\%)\end{array}$ \\
\hline $\begin{array}{l}\text { E. grandis } \\
\text { Composta }\end{array}$ & $44,4 \pm 0,4 *$ & $0,12 * *$ & $79,1 \pm 0,2 *$ \\
E. globulus & $40,6 \pm 0,3$ & 0,11 & $77,3 \pm_{0}, 2$ \\
E. degiupta & $43,2 \pm 0,2$ & 0,13 & $79,0 \pm 0,2$ \\
Betula verrucosa & $41,5 \pm 0,6$ & 0,16 & $82,3 \pm 0,1$ \\
Gmelina arborea & $46,6 \pm 0,5$ & 0,14 & $78,5 \pm 0,2$ \\
Pinheiro & $30,6 \pm 0,2$ & 0,18 & $81,7 \pm 0,1$ \\
\hline
\end{tabular}

* intervalo de confiança à nível de 95\% de probabilidade.

** repetições não exibem diferenças significativas à nivel de $95 \%$ de probabilidade. 
E interessante observar os resultados da polpa de Gmelina arborea, pois essa polpa apresentou baixo número de fibras por grama, comparando com as demais espécies, mas o coeficiente de espalhamento da luz e a opacidade só foram inferiores a polpa de $E$. deglupta que apresentou o segundo maior número de fibras. No entanto, nota-se que a polpa de gmelina possui elevada percentagem definos, e o maior número desses pequenos elementos certamente deve ter aumentado o espalhamento de luz. Além disso, o elevado conteúdo de extrativos dessa polpa (Tabela 28, apresentada no Apêndice), aumentou o coeficiente de absorção de luz, e con sequentemente, a opacidade.

A partir dos resultados que foram obtidos para os diversos tipos de polpa estudadas, foi de interesse verificar estatisticamente o nível de correlação existente entre as propriedades de espalhamento de luz e de opacidade do papel e as características anatômicas das fibras.

\subsubsection{Análise de regressão linear}

Pela análise estatística, apresentada na Tabela 15, ficou demonstrado que existe correlação significativa entre número de fibras por grama e as propriedades óticas do papel (coeficiente de espalhamento de luz e opací dade), através dos valores obtiảos para os coeficientes de 
correlação linear entre as variáveis. Estas correlações tam bém podem ser observadas nos Gráficos 1 e 2 .

Tabela 15 - Regressões lineares obtida entre o número de fí bras por grama $(x)$ e o coeficiente de espalhamento de luz e opacidade (y) das polpas estudadas (modelo: $y=a+b x$ ).

\begin{tabular}{lccc}
\hline Polpas & Coce. Espahihamento luz & Opacidade \\
\hline Separadas no & a & 31,11 & 73,91 \\
"Bauer McNett" & b & 0,55 & 0,38 \\
& r & $0,88 * *$ & $0,60 * *$ \\
Produzidas em & a & 28,70 & 74,43 \\
Laboratório & b & 0,56 & 0,24 \\
\hline & r & $0,98 * *$ & $0,99 * *$ \\
Comerciais & a & 30,73 & 72,06 \\
& b & 0,69 & 0,39 \\
\hline
\end{tabular}

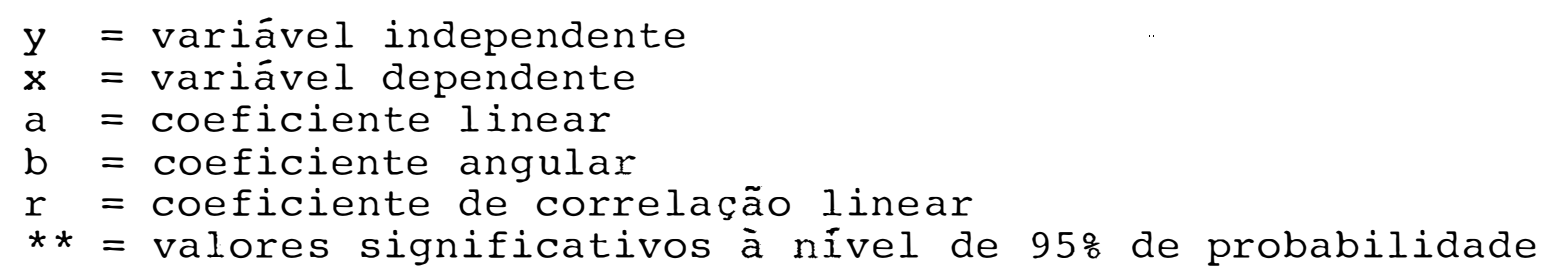




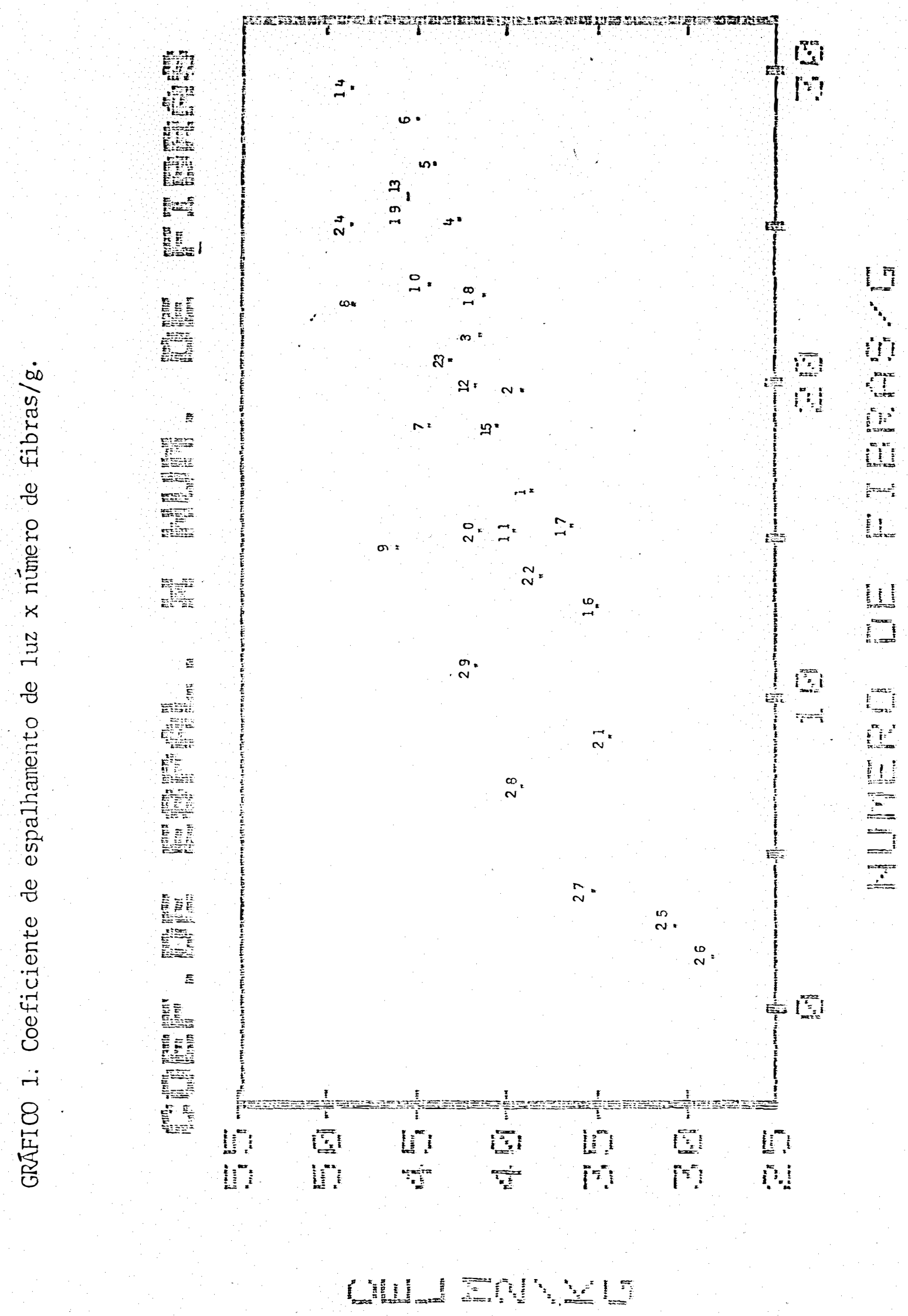

.47 
. .48.

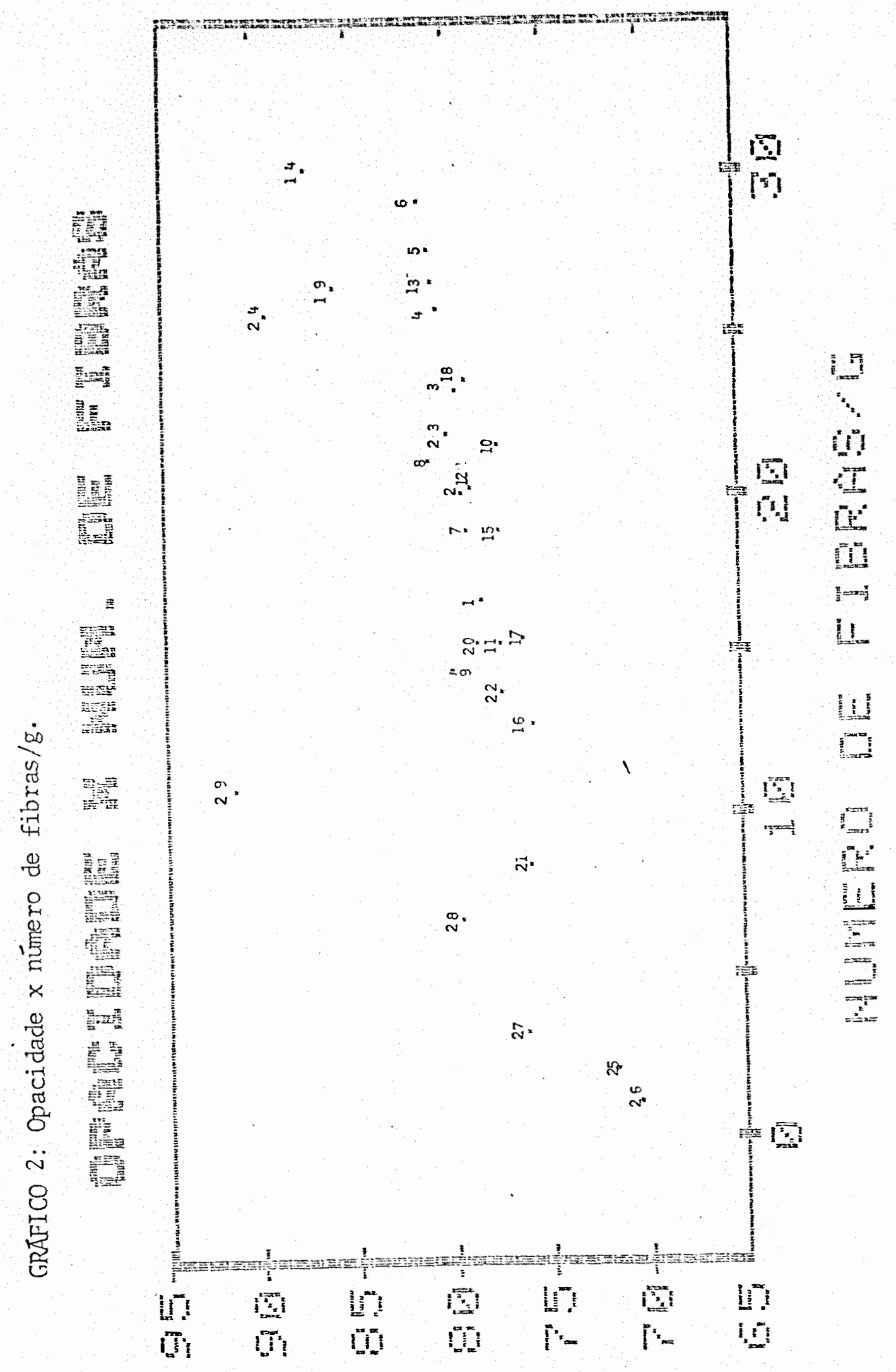

GHMWHLU 
seguir:

01. A (região próximo à casca)

02 . B ( $80 \%$ região da casca e $20 \%$ região da medula)

03. C (60\% região da casca e 40\% região da medula)

04. D (40\% região da casca e 60\% região da medula)

05. E (20\% região da casca e $80 \%$ região da medula)

06. F (região próxima à medula)

07. E. grobuzus

08. E. deglupta

09. Gmelina arborea

10. E. grandis (original)

11. E. grandis (R-30)

12. E. grandis $(\mathrm{P}-30 / \mathrm{R}-50)$

13. E. grandis (P-50/R-100)

14. E. grandis (P-100)

15. Composta (original)

16. Composta $(\mathrm{R}-30)$

17. Composta $(P-30 / R-50)$

18. Composta $(\mathrm{P}-50 / \mathrm{R}-100)$

19. Composta $(\mathrm{P}-100)$

20. Betula verrucosa (original)

21. Betula verrucosa (R-30)

22. Betula verrucosa ( $\mathrm{P}-30 / \mathrm{R}-50)$

23. Betula verrucosa ( $\mathrm{P}-50 / \mathrm{R}-100)$

24. Betula verrucosa (P-100)

25. Pinheiro (original)

26. Pinheiro $(\mathrm{R}-30)$

27. Pinheiro $(\mathrm{P}-30 / \mathrm{R}-50)$

28. Pinheiro $(\mathrm{P}-50 / \mathrm{R}-100)$

29. Pinheiro $(\mathrm{P}-100)$ 
No Gráfico 2, pode-se notar também que quatro polpas, referentes as frações P-100 de E. grandis, composta, pinheiro e betula possuem opacidades muito superiores às das demais polpas, o que pode ser explicado pelo alto coeficiente de absorção dessas polpas, causado provavelmente pelos altos teores de extrativos em etanol-tolueno e dicloro-metano (Tabelas 26 e 27 do Apêndice).

Dessa maneira, os resultados das correlações lineares comprovam a importância do número de fibras por grama para diversos tipos de polpas estudadas, desde àquelas produzidas com diferentes comprimento de fibras (se paradas pelo "Bauer McNett" ou geradas a partir de regiões diferentes da madeira de uma mesma árvore), como para as polpas comerciais de várias espécies, abrangendo uma ampla faixa de características anatômicas. 


\subsection{Propriedades físico-mecânicas}

Para complementação do estudo das influências das caracteristicas anatômicas sobre as proprieda des do papel, foram avaliadas também as propriedades físico -mecânicas das polpas analisadas anteriormente.

De maneira geral, nota-se para as polpas classificadas pelo "Bauer McNett", que as propriedades apresentadas nas Tabelas 16 a 19, tenderam a aumentar a par tir da fração $R-30$ para $\mathrm{P}-100$. Comportamento semelhante foi encontrado para as polpas produzidas em laboratório, quando se aumentou a proporção de polpa da região da madeira mais próxima à medula (Tabela 20).

Estas propriedades, dependentes do grau de interligação das fibras, como densidade aparente e os in dires de tração e estouro, demonstraram incrementos com a re dução do comprimento das fibras, provavelmente devido ao fa to que também aumentaram neste sentido o número de fibras por grama. Assim, as polpas com mais fibras produziram papéis com maìor número de ligações entre fibras e com estrutura mais consolidada. 
Tabela 16 - Densidade aparente $\left(\mathrm{kg} / \mathrm{m}^{3}\right)$ das polpas separadas no "Bauer McNett".

\begin{tabular}{lcccc}
\hline & $E$. grandis & composta & Betula & Pinheiro \\
\hline $\mathrm{R}-30$ & $516 \pm 3 *$ & $476 \pm 3$ & $591 \pm 2$ & $452 \pm 2$ \\
$\mathrm{P}-30 / \mathrm{R}-50$ & $535 \pm 3$ & $489 \pm 2$ & $603 \pm 2$ & $547 \pm 3$ \\
$\mathrm{P}-50 / \mathrm{R}-100$ & $554 \pm 3$ & $528 \pm 2$ & $628 \pm 1$ & $547 \pm 2$ \\
$\mathrm{P}-100$ & $695 \pm 5$ & $653 \pm 3$ & $660 \pm 2$ & $688 \pm 4$ \\
\hline
\end{tabular}

* intervalo de confiança à nível de $95 \%$ de probabilidade

Tabela 17 - Indice de tração (Nm/g) das polpas separadas no "Bauer McNett".

\begin{tabular}{lcccc}
\hline & E. grandis & Composta & Betula & Pinheiro \\
\hline R-30 & $18,0 \pm 0,5 *$ & $13,6 \pm 0,3$ & $19,8 \pm 0,4$ & $6,7 \pm 0,5$ \\
P-30/R-50 & $18,5 \pm 0,4$ & $13,4 \pm 0,2$ & $18,6 \pm 0,4$ & $13,2 \pm 0,4$ \\
P-50/R-100 & $20,5 \pm 0,5$ & $16,4 \pm 0,3$ & $21,0 \pm 0,5$ & $14,8 \pm 0,6$ \\
P-100 & $35,6 \pm 0,8$ & $33,0 \pm 0,6$ & $29,6 \pm 0,6$ & $31,0 \pm 0,6$ \\
\hline * intervalo de confiança à nível de $95 \%$ de probabilidade
\end{tabular}


Tabela 18 - Indice de estouro $\left(\mathrm{kPa} \mathrm{m}^{2} / \mathrm{g}\right)$ das polpas separadas no "Bauer McNett".

\begin{tabular}{lcccc}
\hline & E. grandis & Composta & Betula & Pinheiro \\
\hline R-30 & $0,79 \pm 0,03^{*}$ & $0,52 \pm 0,05$ & $0,81 \pm 0,02$ & $0,28 \pm 0,04$ \\
P-30/R-50 & $0,79 \pm 0,02$ & $0,49 \pm_{0,02}$ & $0,77 \pm 0,02$ & $0,72 \pm 0,02$ \\
P-50/R-100 & $0,93 \pm 0,03$ & $0,64 \pm_{0}, 03$ & $1,01 \pm 0,03$ & $0,79 \pm 0,03$ \\
P-100 & $2,12 \pm 0,05$ & $1,88 \pm_{0}, 05$ & $1,47 \pm 0,03$ & $1,55 \pm 0,02$ \\
* intervalo de confiança à nível de $95 \%$ de probabilidade
\end{tabular}

Tabela 19 - Indice de rasgo $\left(\mathrm{Nm}^{2} / \mathrm{kg}\right)$ das polpas separadas no "Bauer McNett".

\begin{tabular}{lcccc}
\hline & $E$. grandis & Composta & Betula & Pinheiro \\
\hline R-30 & $3,7 \pm 0,2^{*}$ & $2,9 \pm 0,2$ & $4,6 \pm 0,2$ & $5,3 \pm 0,3$ \\
P-30/R-50 & $3,3 \pm 0,1$ & $2,4 \pm 0,1$ & $3,1 \pm 0,2$ & $5,5 \pm 0,4$ \\
P-50/R-100 & $3,2 \pm 0,2$ & $2,5 \pm 0,2$ & $3,1 \pm 0,4$ & $4,2 \pm 0,2$ \\
P-100 & $6,1 \pm 0,1$ & $5,5 \pm 0,4$ & $3,7 \pm 0,2$ & $4,3 \pm 0,1$ \\
* intervalo de confiança à nível de $95 \%$ de probabilidade
\end{tabular}

* intervalo de confiança à nível de $95 \%$ de probabilidade 


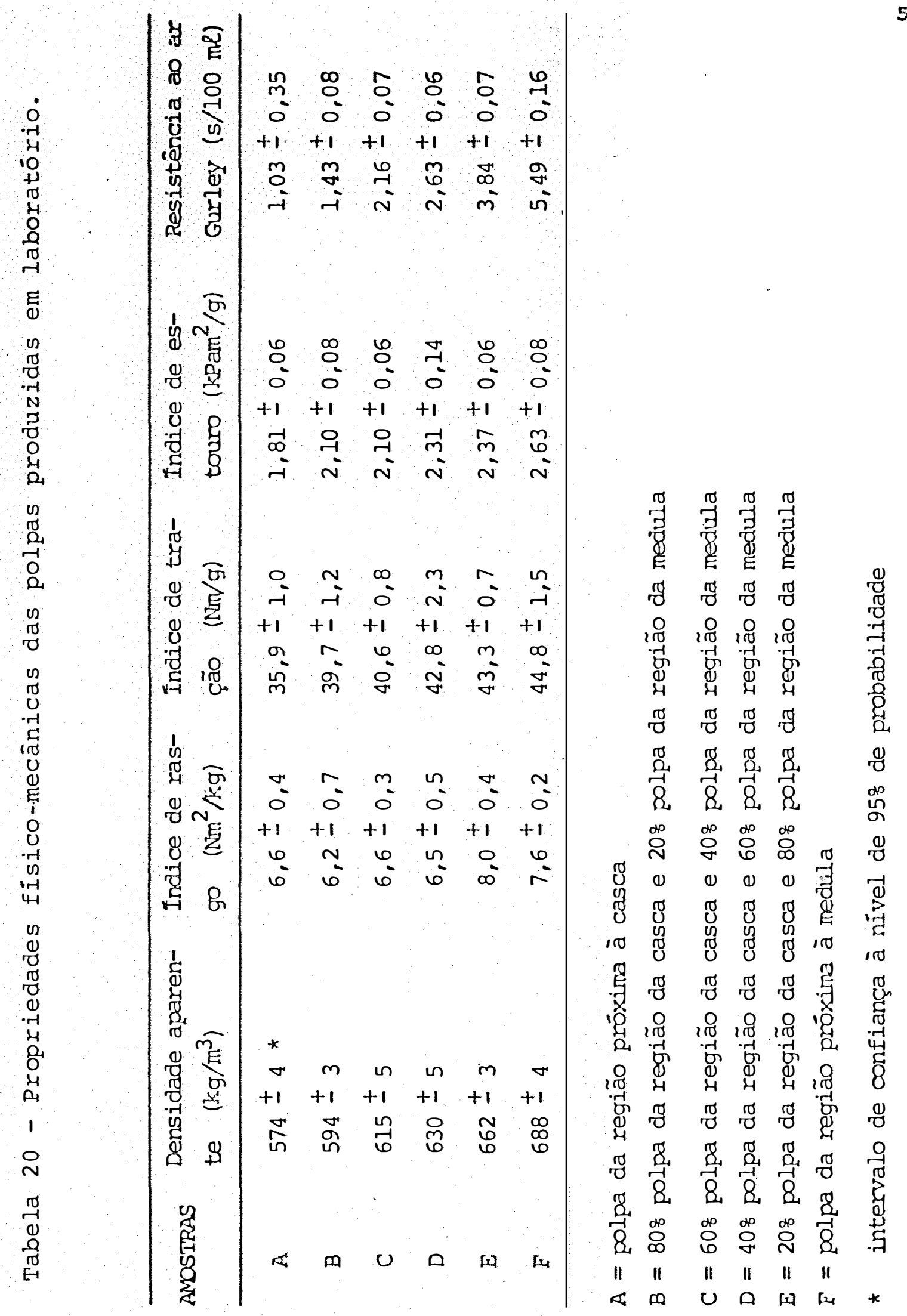


No entanto, as frações $\mathrm{P}-100$ das quatro espécies estudadas, mostraram valores muito superiores aos das demais frações para maioria das propriedades físicas estudadas, o que provavelmente se deve ao seu alto teor de finos que acompanham essas frações, em função da classi ficação que as fibras sofreram pelo "Bauer McNett", que levaram os finos a se concentrar na última fração. Resultados semelhantes foram apresentados por HTUN \& RUVO (1978), estu dando polpa Kraft branqueada e classificada em cinco peneiras pelo "Bauer McNett", encontrando nas folhas produzidas a partir de polpas de finos (fração que passou pela peneira de 200 mesh) propriedades mecânicas comparáveis às folhas feitas com a polpa original (sem separação das fibras). Esses autores concluiram que os finos possuem alta dilatação (inchamento) o que possibilita adaptarem-se à estrutura e contribuir para uniforme distribuição das forças no papel, obtendo-se um produto mais forte e uniforme.

Em relação as polpas comerciais, essas propriedades também parecem ter sido beneficiadas pelo aumento do número de fibras por grama, uma vez que os maiores indices de tração e estouro foram obtidos pelo $E$. deglupta e E. grandis, (Tabela 21), sendo essas as espécies com maior número de fibras por grama.

A tendência geral foi de aumento dos indices de tração e estouro com maior número de fibras por grama, como pode ser verificado pelos Gráficos 3 e 4 . 


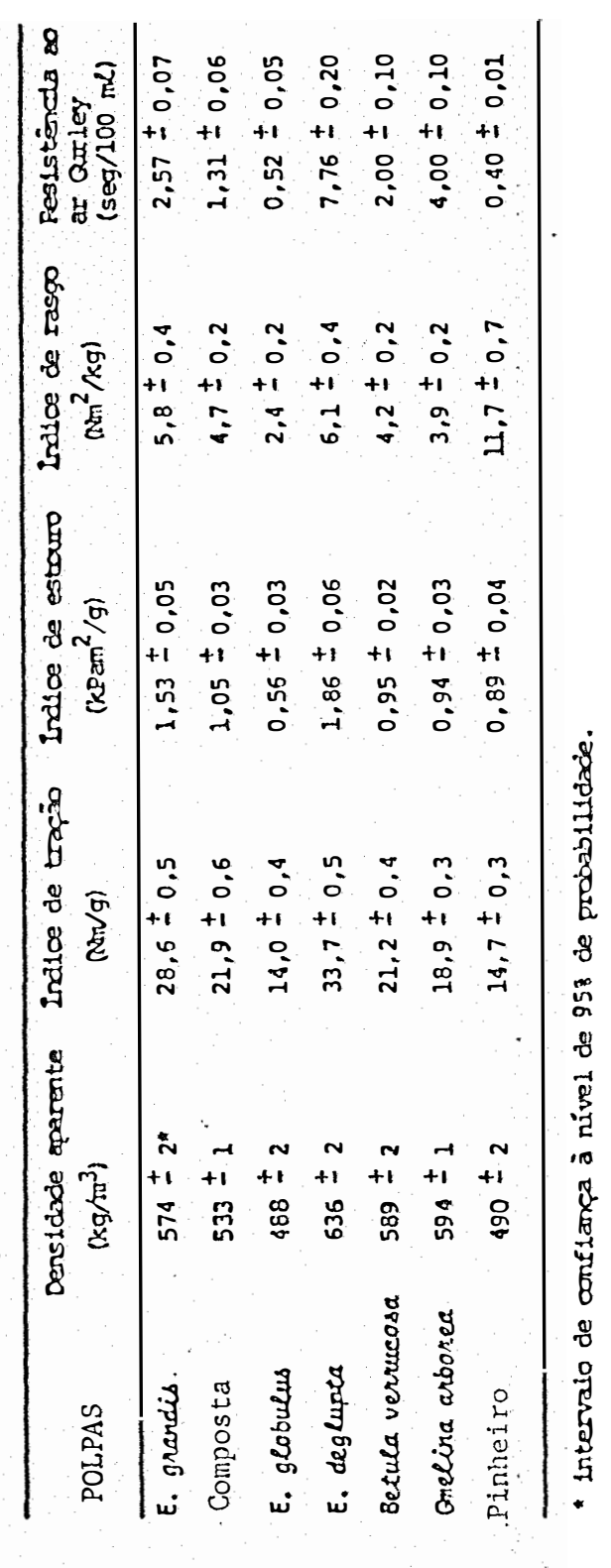




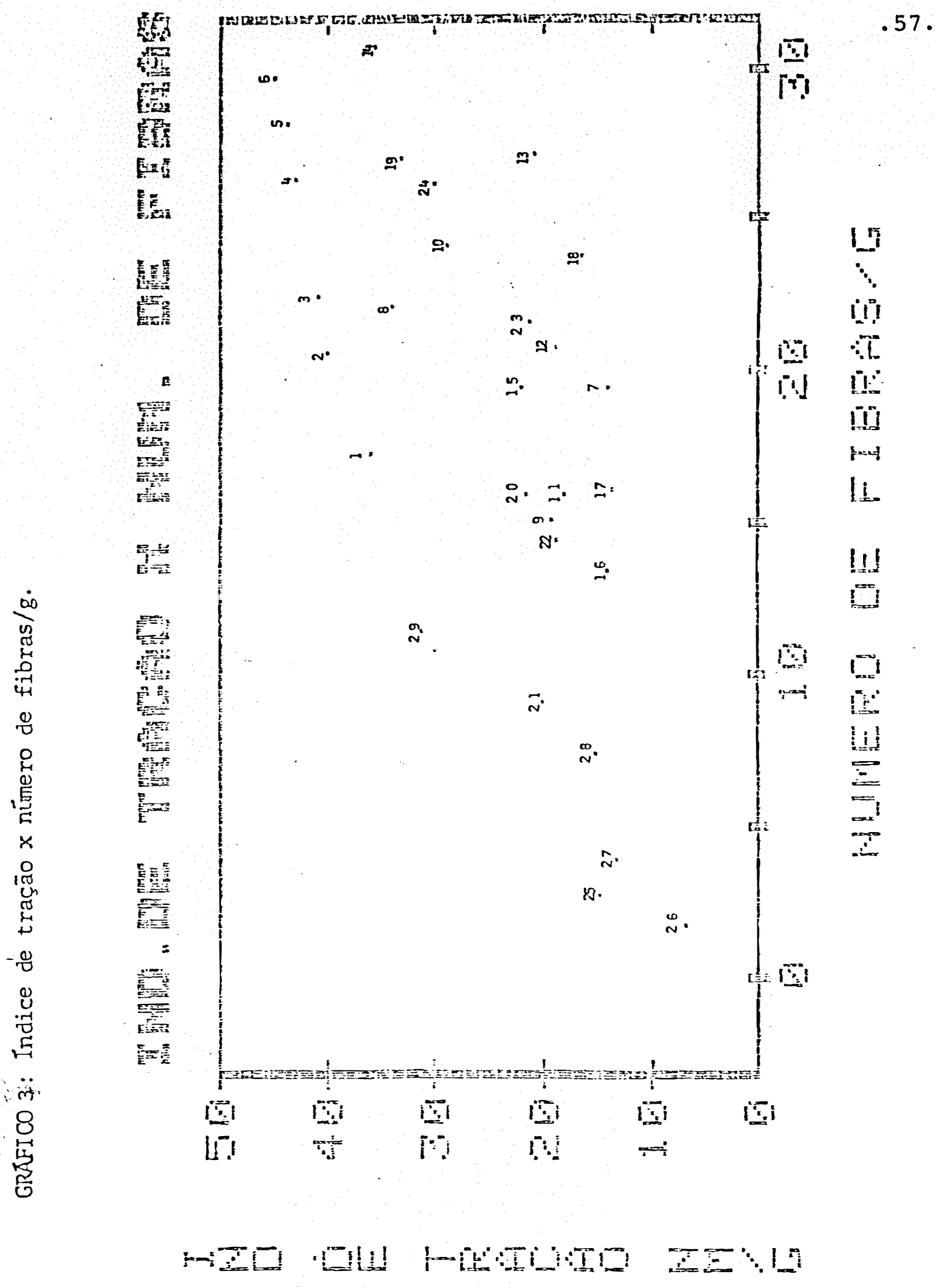




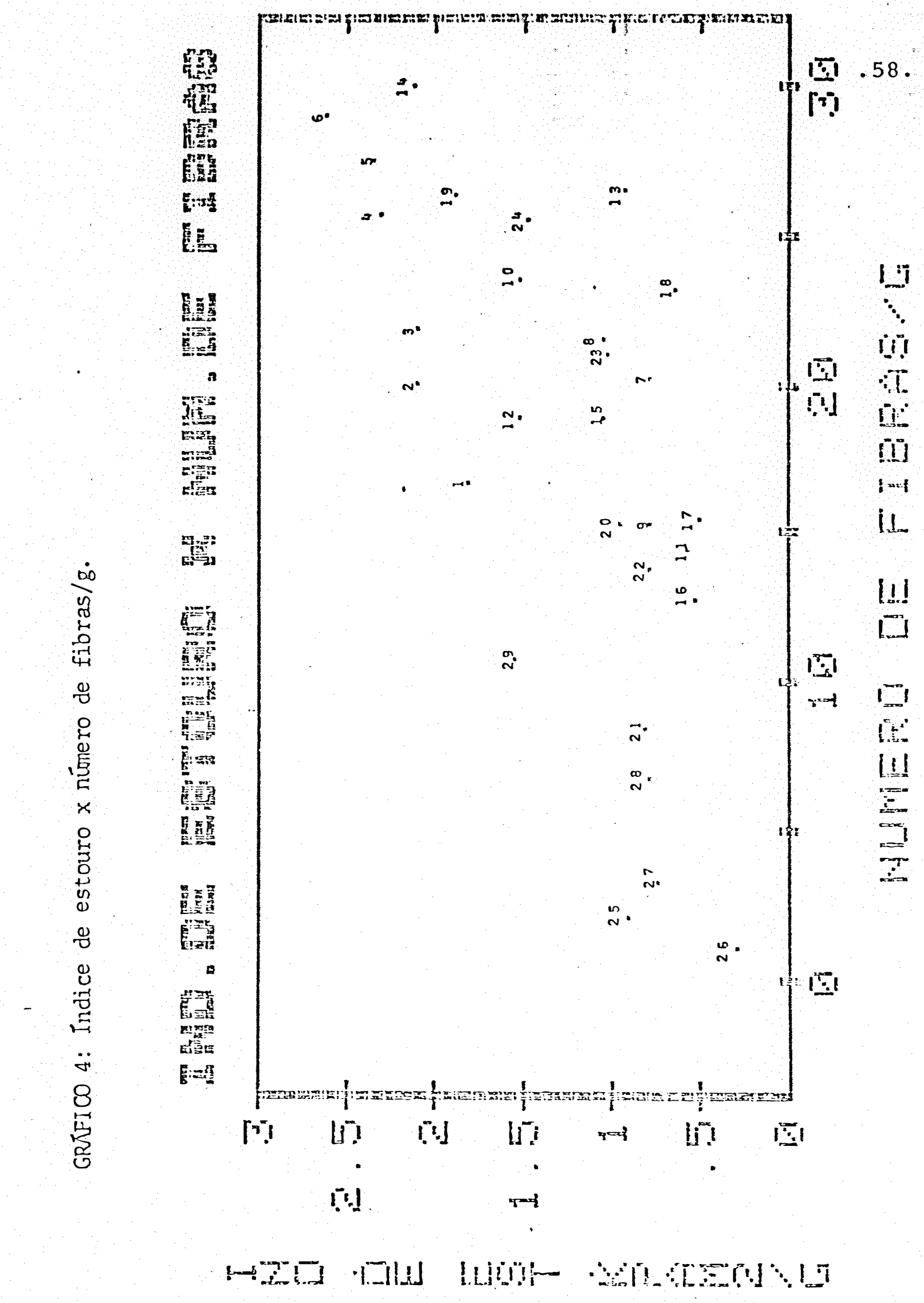


A identificação das polpas é feita a

seguir:

01. A (região próximo à casca)

02 . B (80\% região da casca e $20 \%$ região da medula)

03. C (60\% região da casca e $40 \%$ região da medula)

04 . D (40\% região da casca e $60 \%$ região da medula)

05. E ( $20 \%$ regiãọ da casca e $80 \%$ região da medula)

06. F (região próxima à medula)

07. E. grobuzus

08. E. deglupta

09. Gmelina arborea

10. E. grandis (original)

11. E. grandis $(\mathrm{R}-30)$

12. E. grandis $(\mathrm{P}-30 / \mathrm{R}-50)$

13. E. grandis $(\mathrm{P}-50 / \mathrm{R}-100)$

14. E. grandis $(\mathrm{P}-100)$

15. Composta (original)

16. Composta $(R-30)$

17. Composta $(\mathrm{P}-30 / \mathrm{R}-50)$.

18. Composta $(\mathrm{P}-50 / \mathrm{R}-100)$

19. Composta $(\mathrm{P}-100)$

20. Betuza verrucosa (original)

21. Betula verrucosa $(\mathrm{R}-30)$

22. Betula verrucosa $(\mathrm{P}-30 / \mathrm{R}-50)$

23. Betula verrucosa $(\mathrm{P}-50 / \mathrm{R}-100)$

24. Betula verrucosa $(\mathrm{P}-100)$

25. Pinheiro (original)

26. Pinheiro $(\mathrm{R}-30)$

27. Pinheiro $(\mathrm{P}-30 / \mathrm{R}-50)$

28. Pinheiro $(\mathrm{P}-50 / \mathrm{R}-100)$

29. Pinheiro $(\mathrm{P}-100)$ 
Além de ligações entre fibras em maior quantidade, ocasionado pelo grande número de fibras por gra ma, o maior teor de pentosanas das últimas frações classifi cadas pelo "Bauer McNett" (Tabela 22) e também das polpas com maior percentagem de fibras da região próxima da medula (Tabela 23), deve ter auxiliado as ligações das fibras dessas polpas, produzindo papéis com maiores índices de resistência físico-mecânicas.

Tabela 22 - Teor de péntosanas $\left(\frac{8}{)}\right.$ das polpas separadas no "Bauer McNett".

\begin{tabular}{|c|c|c|c|c|}
\hline & E. grandis & Composta & Betula & Pinheiro \\
\hline$R-30$ & $14,8^{*}$ & 15,0 & 23,2 & 7,4 \\
\hline$P-30 / R-50$ & 15,6 & 15,6 & 25,3 & 8,2 \\
\hline$P-50 / R-100$ & 16,2 & 16,4 & 25,6 & 8,6 \\
\hline $\mathrm{P}-100$. & 18,0 & 18,0 & 28,8 & 9,3 \\
\hline
\end{tabular}

* determinações em duplicata 
Tabela 23 - Composição química das polpas produzidas em laboratório.

\begin{tabular}{ccc}
\hline Amostras & Pentosanas $(\%)$ & Extrativos Etanol Tolueno (\%) \\
A & $11,6 *$ & $0,13 *$ \\
B & 12,8 & 0,14 \\
C & 13,9 & 0,12 \\
D & 13,6 & 0,20 \\
E & 14,6 & 0,20 \\
F & 15,0 & 0,20 \\
\hline
\end{tabular}

$A=$ polpa da região próxima à casca.

$\mathrm{B}=80 \%$ polpa da regĩão da casca e $20 \%$ polpa da região da medula.

$C=60 \%$ polpa da região da casca e 40\% polpa da região da medula.

$D=40 \%$ polpa da região da casca e 60\% polpa da região da medula.

$E$ - $20 \%$ polpa da região da casca e $80 \%$ polpa da região da medula.

$\mathrm{F}=$ polpa da região próxima à medula.

* = determinações em duplicata.

Em relação a resistência ao ar Gurley, apresentada na Tabela 24, este também se mostrou crescente da polpa R-30 para P-100, confirmando uma maior consolida ção da folha de papel,o que concorda com as observações de DINWOODIE (1965) e ENRICH (1985).

Neste caso novamente, se verificou que o aumento do numero de fibras por grama e da quantidade de 
finos, resultaram num maior numero de ligações, diminuindo - tamanho dos poros. Como o volume de ar que passa pelos ca pilares é função direta do raio desses capilares (MURAKAMI \& IMAMURA, 1983), com a diminuição do tamanho dos poros, di minuiu-se a porosidade da folha de papel, ocasionando maior resistência à passagem do ar.

Por outro lado, entre as polpas comerciais, a resistência ao ar mostrou maiores valores para as polpas com elevado número de fibras e de finos, com exceção do $E$. globulus, que embora tenha mostrado alto número de fi bras por grama, a resistência ao ar foi baixa; entretanto, deve-se considerar também a flexibilidade de suas fibras. Provavelmente as fibras mais rígidas lalta densidade básica da madeiral podem ter proporcionado aos papéis de $E$. gl $\bullet-$ bulus, uma estrutura mais aberta, deixando maiores espaços entre fibras, apesar destas ocorrerem em grande número por unidade de peso. 
Tabela 24 - Resistência ao ar Gurley (s/100 ml) das polpas separadas no "Bauer McNett".

\begin{tabular}{lrrrr}
\hline & E. grandis & Composta & Betula & Pinheiro \\
\hline R-30 & $0,47 \pm 0,02^{*}$ & $0,23 \pm 0,02$ & $0,60 \pm 0,08$ & $0,16 \pm 0,03$ \\
P-30/R-50 & $0,68 \pm 0,02$ & $0,28 \pm 0,02$ & $0,90 \pm 0,09$ & $0,75 \pm 0,07$ \\
P-50/R-100 & $1,21 \pm 0,03$ & $0,63 \pm 0,01$ & $2,40 \pm 0,10$ & $1,58 \pm 0,05$ \\
P-100 & $42,67 \pm 0,61$ & $21,12 \pm 0,67$ & $18,80 \pm 0,70$ & $469,3 \pm 36,6$ \\
\hline
\end{tabular}

* intervalo de confiança à nível de $95 \%$ de probabilidade

Portanto, as polpas com maior número de fibras por gramá apresentaram maior área de exposição das fibras e mais interfaces fibra-ar, aumentando o espalha mento da luz e a opacidade do papel. Ao mesmo tempo, este parâmetro também aumentou a área de ligação entre fibras,re sultando em maiores indices de resistência físico-mecânicas. 


\section{CONCLUSÕES}

Da discussão dos resultados podem ser tiradas as seguintes conclusões:

1. As polpas comerciais, fracionadas ou não, e as provenien tes de diferentes regiões da seç̧ão transversal da madei ra, mostraram diferenças importantes em termos de características de fibras, "coarseness" e número de fibras por grama.

2. As polpas contendo maior número de fibras produziram papéis com maiores coeficientes de espalhamento de luz e opacidade. Esta observação se apoia no fato da existência de elevado número de espaços intercelulares, o que obriga a luz a atravessar mais interfaces fibra-ar. 
3. Os resultados da análise estatistica confirmaram, para os diversos tipos de polpas estudados, alta correlação linear entre o número de fibras por grama e as proprieda des de espalhamento de $l u z$ e opacidade.

4. As propriedades que dependem do grau de ligação entre fi bras, como densidade aparente e as resistências à tração e ao estouro, mostraram maiores índices nas polpas com mais fibras por grama. Isto comprova que esta caracterís tica proporciona mais pontos de contato, aumentando o nu mero de ligações. Ao mesmo tempo, se observou nessas polpas maior resistência ao ar Gurley. 
.66 .

\section{LITERATURA CITADA}

BARRICHELO, L.E.G. \& J.O. BRITO, 1979. A utilização da madeira na produção de celulose. Circular técnica. IPEF; Piracicaba, (68): 1-16.

BARRICHELO, L.E.G.; J.O. BRITO \& A.V. BAZANELLI, 1983. Densidade básica e características das fibras de madeira de Eucalyptus grandis In: CONGRESSO LATINO-AMERICANO DE CELUlose E PAPEL, 3, São Paulo 21-26 nov. v. 1 $\mathrm{p}: 113-25$ 
BRASIL, M.A.M., 1976. Densidade básica e características das fibras da madeira de Eucalyptus grandis Hill ex Maiden aos 3 anos de idade. Piracicaba, ESALQ/USP, 126 p. (Tese de Doutoramento).

BRITT, K.W., 1966. Fiber coarseness in wood. TAPPI, Atlanta, $49(5): 202-6$.

CARPIM, M.A., R.V. SOUZA \& L.E.G. BARRICHELO, 1985. Comparação das caracteristicas da madeira de Eucalyptus grandis e Eucalyptus saligna de diferentes procedências. In: CONGRESSO ANUAL ABCP, 18, São Paulo, 18-22 nov. v. $1 p: 57-68$.

CASEY, J.P., 1960. Pulp and paper: chemistry and chemical technology. 2a ed. New York, Interscience. $3 \mathrm{v}$.

CLARK; J.A., 1978. Pulp technology and treatment for paper. San Francisco, Miller Freeman. 751 p.

CLAUDIO-DA-SILVA JR., E. 1981. - "Chemical pulp beating related to fiber structure" - Syracuse. College of Environmental Science and Forestry. 295 p. (TeseDoutorado-SUNY) . 
CLAUDIO-DA-SILVA, JR., E., 1983. Flexibility of pulp fibers a estructural approach. In: INTERNATIONAL PAPER PHYSICS CONFERENCE, p. 13-25.

COLLEY, J., 1973. Properties of blends of high and low density eucalypt pulps. APPITA, Melbourne, $26(6): 430-6$

DINWOODIE, J.M., 1965. The relation between fiber morphology and paper properties: a review of literature. TAPPI, Atlanta, $48(8): 440-7$.

ENRICH, R.V., 1985. Desarrollo de las propriedades de resistencia del papel. Ingenieria Quimica: 55-62, abr.

FOELKEL, C.E.B. et $a$ lii, 1976. Celulose kraft de madeira juvenil e adulta de Pinus elliottii. IPEF, Piracicaba, (12) : 127-42.

GIERTZ, H.W., 1965. Some optical consequences of consolidation of paper. In: CONSOLIDATION OF THE PAPER WEB. TRANSACTIONS OF THE CAMBRIDGE SYMPOSIUM, London, p. $928-33$. 
GOETZLER, M., 1982. Final inter committee report on toluene substitution for benzene in TAPPI analytical procedures. PAPPI, Atlanta, 65(3):149-50.

HASUIKE, M. \& K. MURAKAMI, 1985. Evaluation of optical characteristics based upon structural parameters of pulp sheet. In: PULP AND PAPER TECHNOLOGY CONFERENCE, Tokyo, out. 1985. Preprints. Tokyo, Japanese TAPPI. p. $173-180$.

HIGGINS, H.G. et alii, 1973. The density and structure of hardwoods in relation to paper surface characteristics and other properties. TAPPI, Atlanta, 56(8) 127-131.

HILLEND, W.J. 1966. Opacity problems in printing papers: Kubelka-Munk theory gives good, quick answers. TAPPI, Atlanta, $49(7): 41-47$.

HTUN, M. \& A. de RUVO, 1978. The implication of the fines fraction for the properties of bleached kraft sheet. Svensk Papperstidning, Stockholm, 16:507-10.

KIBBLEWHITE, R.P., 1973. Effects of beating and wood quality on radiata pine kraft properties. New Zealand Journal of Forestry Science, Rotorua, 3(2):220-39. 
KIBBLEWHITE, R.P., 1979. Application of fibre characterization techniques to industrial papermaking operations. APPITA, Melbourne, 33(2):111-8.

KIBBLEWHITE, R.P., 1984. Fibres and fines of some radiata pine corewood and slabwood thermomechanical and refiner mechanical pul.ps. APPITA, Melbourne, 37(8):650-7.

LAW, K.N. \& Z. KORAN, 1981. Effect of press drying on paper properties. APPITA, Melbourne, 34(5):387-90.

LONNBERG, B., 1976. Short-rotation hardwood species as wholetree raw material for pulp and paper. Paperi Ja Puu, Helsinki, $58(8): 445-60,463-6,469-72$.

MURAKAMI, K. \& R. IMAMURA, 1983. Porosity and gas permeability. In: MARK, R.E. Handbook of physical and mechanical testing of paper and paperboard. New York, Marcel Dekker, Inc. v. 1 .

NICHOLLS, G.A. \& R.G. JAMIESON, 1976. Relating kraft pulp quality differences to raw material variation without wood samples. APPITA, Melbourne, 29(5):339-43. 
NORDMAN, L., P. AALTONEN \& T. MAKKONEN, 1965.

Relationships between mechanical and optical properties of paper affected by web consolidation. In: CONSOLIDATION OF THE PAPER WEB TRANSACTIONS OF THE CAMBRIDGE SYMPOSIUM, London, p. 909-927.

NORDMAN, L., 1970. Opacity and pulp properties. Papierweseld. The Finninsh Pulp and Paper Research Institute, Helsinki, (451):1-111

ROBINSON, J.V. 1975. A summary of reflectance equations for application of the Kubelka-Munk theory to optical properties of paper. TAPPI, Atlanta, 58(10):152-153.

ROBINSON, J.V., 1976. Optical properties of paper as affected by wet-end chemistry. TAPPI, Atlanta, $59(2): 77-84$

SCALLAN, A.M. 1985. An alternative approach to the Kubelka-Munk theory. Journal of Pulp and Paper Science, Montreal, $11(3): 80-84$. 
SCALLAN, A.M. \& J. BORCH, 1972. An interpretation of paper reflectance based upon morphology: inicial considerations. TAPPI, Atlanta, 55(4):583-588.

SCALLAN, A.M. \& J. BORCH, 1974. An interpretation of paper reflectance based upon morphology: general applicability. TAPPI, Atlanta, 57(5):143-147.

SCALLAN, A.M. \& J. BORCH, 1976a. An interpretation of paper reflectance based upon morphology: the effect of mass distribution. TAPPI, Atlanta, 59(10):102-105.

SCALLAN, A.M. \& J. BORCH, 1976b. Fundamental parameters affecting the opacity and brightness of uncoated paper. In: BOLAM, F. Ed. The fundamental properties of paper related to its uses. London. The British Paper and Board Industry Federation. p. 152-171.

SCAN (s.d.). Testing procedures of Scandinavian pulp, paper and board. Stockholm.

TAPPI (s.d.). Testing procedures of Technical Association of Pulp and Paper Industry. Atlanta. 
UPRICHARD, J.M. \& J.T. GRAY, 1972. Pulps from New Zealand grown Corsian pine. APPITA, Melbourne, $26(1): 39-42$.

UPRICHARD, J.M., 1973. Effects of wood age on optical and strength properties of softwood kraft pulps. APPITA, Melbourne, $\quad 27(3): 179-184$. 
.74.

APÊNDICE 
Tabela 25 - Teor de cinzas (8) das polpas separadas no "Bauer McNett".

\begin{tabular}{|c|c|c|c|c|c|}
\hline & $E$. & grandis & E. urophyzza & Betula & Pinheiro \\
\hline$R-30$ & & - & - & $0,18 *$ & 0,05 \\
\hline$P-30 / R-50$ & & - & - & 0,18 & 0,08 \\
\hline$P-50 / R-100$ & & - & - & 0,28 & 0,13 \\
\hline$P-100$ & & - & - & 1,58 & 0,50 \\
\hline
\end{tabular}

* determinações em duplicata

Tabela 26 - Teor de extrativos em diclorometano ( $?$ ) das pol pas separadas no Bauer McNett.

\begin{tabular}{lcccc}
\hline & $E$. grandis & E. urophyzla & Betula & Pinheiro \\
\hline $\mathrm{R}-30$ & - & - & $0,03^{*}$ & 0,02 \\
$\mathrm{P}-30 / \mathrm{R}-50$ & - & - & 0,06 & 0,02 \\
$\mathrm{P}-50 / \mathrm{R}-100$ & - & - & 0,13 & 0,04 \\
$\mathrm{P}-100$ & - & - & 1,49 & 0,15 \\
\hline
\end{tabular}

* determinações em duplicata 
Tabela 27 - Teor de extrativos em etanol/tolueno

(8) das polpas separadas no "Bauer McNett".

\begin{tabular}{lcccc}
\hline & E. grandis & E. urophylza & Betula & Pinheiro \\
\hline R-30 & $0,08^{*}$ & 0,07 & 0,08 & 0,05 \\
$\mathrm{P}-30 / \mathrm{R}-50$ & 0,05 & 0,09 & 0,09 & 0,03 \\
$\mathrm{P}-50 / \mathrm{R}-100$ & 0,08 & 0,07 & 0,16 & 0,06 \\
$\mathrm{P}-100$ & 0,42 & 0,36 & 1,58 & 0,19 \\
\hline
\end{tabular}

* determinações em duplicata

Tabela 28 - Composição química das polpas comerciais.

\begin{tabular}{|c|c|c|c|c|}
\hline \multirow[b]{2}{*}{ Espécie } & \multicolumn{2}{|c|}{ Extrativos } & \multirow[b]{2}{*}{$\begin{array}{c}\text { Pentosanas } \\
\left(\frac{\circ}{0}\right)\end{array}$} & \multirow[b]{2}{*}{$\begin{array}{c}\text { Cinzas } \\
(\%)\end{array}$} \\
\hline & $\begin{array}{l}\text { clorometano } \\
\left(\frac{\circ}{0}\right)\end{array}$ & $\begin{array}{c}\text { Etanol/toluneno } \\
(\%)\end{array}$ & & \\
\hline E. grandis. & $0,10 *$ & 0,15 & 15,8 & 0,13 \\
\hline E. urophyzza & 0,11 & 0,15 & 15,8 & 0,13 \\
\hline E. grobuzus & 0,08 & 0,15 & 18,7 & 0,08 \\
\hline E. degrupta & 0,15 & 0,21 & 18,1 & 0,19 \\
\hline Betula vermucos $\alpha$ & 0,72 & 0,86 & 25,1 & 0,99 \\
\hline Gme lina arborea & $a 0,68$ & 0,92 & 16,5 & 0,07 \\
\hline Pinheiro & 0,02 & 0,06 & 7,4 & 0,04 \\
\hline
\end{tabular}

* determinações em duplicata 